\title{
2D LDH-MoS 2 clay nanosheets: synthesis, catalase-mimic capacity, and imaging-guided tumor photo-therapy
}

\author{
Jiayan Zhao ${ }^{1,2+}$, Hang Wu ${ }^{3 \dagger}$, Jiulong Zhao ${ }^{1}$, Yichen Yinn ${ }^{2}$, Zhilun Zhang ${ }^{2}$, Shige Wang ${ }^{2}$ and Kun Lin ${ }^{1 *}$
}

\begin{abstract}
Owing to the hypoxia status of the tumor, the reactive oxygen species (ROS) production during photodynamic therapy (PDT) of the tumor is less efficient. Herein, a facile method which involves the synthesis of Mg-Mn-Al layered double hydroxides (LDH) clay with $\mathrm{MoS}_{2}$ doping in the surface and anionic layer space of LDH was presented, to integrate the photo-thermal effect of $\mathrm{MOS}_{2}$ and imaging and catalytic functions of Mg-Mn-Al LDH. The designed $\mathrm{LDH}-M o S_{2}(\mathrm{LMM})$ clay composite was further surface-coated with bovine serum albumin (BSA) to maintain the colloidal stability of LMM in physiological environment. A photosensitizer, chlorin e6 (Ce6), was absorbed at the surface and anionic layer space of LMM@BSA. In the LMM formulation, the magnetic resonance imaging of Mg-Mn-AI LDH was enhanced thanks to the reduced and acid microenvironment of the tumor. Notably, the ROS production and PDT efficiency of Ce6 were significantly improved, because LMM@BSA could catalyze the decomposing of the overexpressed $\mathrm{H}_{2} \mathrm{O}_{2}$ in tumors to produce oxygen. The biocompatible LMM@BSA that played the synergism with tumor microenvironment is a promising candidate for the effective treatment of cancer.
\end{abstract}

Keywords: $\mathrm{LDH}, \mathrm{MoS}_{2}$, Chlorin e6, Catalysis, Tumor therapy

\section{Introduction}

The methodology of the detection and medical treatment of cancer has seen a rapid growth over the past few decades [1-3]. However, standard clinical therapies of cancer remain with many defects and individual bottlenecks. Surgical resection would cause operative wounds, X-ray exposure may bring serious side effects to healthy tissue because of off-target $[4,5]$, and chemotherapy usually shows limited efficacy with severe multi-drug resistance [6-8]. Thence, the malignant tumor is still posed as one of the greatest enemies of public health $[9,10]$, and novel tumor therapeutic approaches to maximizing the

\footnotetext{
*Correspondence: lin17321171461@163.com

†jiayan Zhao and Hang Wu contributed equally to this work

${ }^{1}$ Department of Gastroenterology, Changhai Hospital, Second Military

Medical University, No. 168 Changhai Road, Shanghai 200433, People's Republic of China

Full list of author information is available at the end of the article
}

treatment efficiency and minimizing the trauma to normal tissue were actively designed. Photon induced tumor therapy, including photothermal therapy (PTT) and photodynamic therapy (PDT), has gained increasing interests in recent years. Tumor PTT relies on the foundation of a photo-thermal transforming agent (PTA) which is capable of transferring the near-infrared (NIR) laser into heat [11-14]. Promisingly, $\mathrm{MoS}_{2}$ has been extensively explored as a PTA owing to its facile fabrication, admirable bio-compatibility, and high photo-thermal conversion efficiency $[15,16]$. As another aspect of photon-induced tumor therapy, PDT primarily involves the killing of cancer cells using the cytoxic reactive oxygen species (ROS), like singlet oxygen $\left({ }^{1} \mathrm{O}_{2}\right)$. The ROS could be produced when the photosensitizer (PS) and intra-tissue oxygen are irradiated by external light [17]. The applications of different kinds of nano-platforms such as gold nanomaterials [18-21], graphene [22-24], and conjugated polymer-composites [25] to load PS (e.g., chlorin e6, Ce6) for 
the synergistic tumor PDT and PTT has been extensively studied. However, owing to the hypoxia status of tumors, the ROS production is limited, leading to an unsatisfactory tumor PDT efficiency [26, 27].

As a kind of frequently studied bio-degradable contrast agent, manganese-based nanomaterials could produce numerous $\mathrm{Mn}$ (II) paramagnetic centers to enhance the $\mathrm{T}_{1}$-weighted MR imaging performance of tumors [28, 29]. More importantly, manganese-based nanomaterials could catalyze the decomposing of the over-expressed hydrogen peroxide $\left(\mathrm{H}_{2} \mathrm{O}_{2}\right)$ to generate oxygen in tumor and alleviate the tumor hypoxia conditions [30]. Many kinds of clay materials are characterized with layer structure and the interlayer space of the clay has been extensively studied for effective drug encapsulation [31]. Layered double hydroxides (LDHs), accompanying with particular physical properties such as high surface area, acidity, and structural stability, is a class of two dimensional (2D) anionic nano-clay with positive-charged layers [32-34]. The internal galleries of LDHs could exchange with other ions in the external environment [35]. Moreover, their physicochemical properties could be adjusted by modulating the ratio of metallic cations and the sort of interlayer anions [36-38]. Recently, the fabrication of LDH-based clay nanocomposites has gained ever-increasing interests. For example, copper $(\mathrm{Cu}(\mathrm{II}))$ or cobalt $(\mathrm{Co}(\mathrm{II}))$ sulfamerazine-salicylaldehyde complexes were used to intercalate the Mg-Al-LDH that was synthesized by a co-precipitation route [39]. In this research, $\mathrm{Mg}$ - $\mathrm{Al}$-LDH composite, which exhibited promising antimicrobial activity against both gram-positive (Staphylococcus aureus) and gram-negative (Escherichia coli) bacteria, was prepared via a two-step delaminating/ restacking method. These motivate us to take the challenge of fabricating an LDH-based composite nano-platform to incorporate the photo-thermal effect of $\mathrm{MoS}_{2}$ for the imaging-guided combined tumor therapy.

Herein, a facile hydrothermal synthesis of LDH$\mathrm{MoS}_{2}$ (LMM) clay nanosheets was proposed. The LMM nanosheets were then surface coated with bovine serum albumin (BSA) to gain the colloidal-stability and biocompatibility in vitro and in vivo. Protein/peptide has been frequently used as the template for the biomimetic mineralization, and has been demonstrated to be an efficient and promising strategy for synthesis of nanoparticles for bioapplications [40]. In this LMM@ BSA formulation, the photo-thermal transforming agent (i.e., $\mathrm{MoS}_{2}$ ) was distributed on the surface and anionic layer space of LDH anionic layer-space the asdesigned LDH. $\mathrm{MoS}_{2}$ provides the possibility to suppress the tumor cell malignant proliferation via NIR laser-induced hyperthermia. At the same time, Mn element renders the LMM@BSA clay nanosheets the tumor reducibility and acidity responsive MR imaging and catalase-mimic capacities to catalyze the disproportionation of $\mathrm{H}_{2} \mathrm{O}_{2}$. The generated oxygen could alleviate the tumor hypoxia conditions to enhance the production of ROS during PDT. The LMM@BSA clay nanosheets were used to efficiently load the photosensitizer Ce6, which could play the synergism with the catalase-mimic capacity of LMM@BSA to enhance the tumor PDT efficiency. To the best of our knowledge, the synthesis of LDH-based nanocomposites with imaging capacity for combined tumor photo-therapy has not been reported yet.

\section{Experimental section}

\section{Synthesis of LMM@BSA clay nanosheets}

All the distilled water applied in this study with a resistivity higher than $18.2 \mathrm{M} \Omega$ was produced using a Milli-Q Plus 185 water purification equipment (Millipore, Bedford, MA). The layered LMM nanosheets were synthesized via a hydrothermal method. Firstly, $0.164 \mathrm{~g} \mathrm{Mg}\left(\mathrm{NO}_{3}\right)_{2} \cdot 6 \mathrm{H}_{2} \mathrm{O}$ (Adamas-beta, Shanghai, China), $0.04 \mathrm{~g} \mathrm{Mn}\left(\mathrm{NO}_{3}\right)_{2} \cdot 4 \mathrm{H}_{2} \mathrm{O}$ (Adamas-beta, Shanghai, China), and $0.06 \mathrm{~g} \mathrm{Al}\left(\mathrm{NO}_{3}\right)_{3} \cdot 9 \mathrm{H}_{2} \mathrm{O}$ (General Reagent, Shanghai, China) were dissolved together in $10 \mathrm{~mL}$ distilled water. The formed aqueous solution was quickly mixed with $20 \mathrm{~mL} \mathrm{NaOH}$ (Aladdin, Shanghai, China, prepared into $0.15 \mathrm{~mol} / \mathrm{L}$ solution). After one hour of magnetic stirring at room temperature, the solution was centrifuged ( 8000 rounds $/ \mathrm{min}, 5 \mathrm{~min}$ ) to collect the sediment. The sediment was then dissolved into $25 \mathrm{~mL}$ distilled water and then mixed with $10 \mathrm{~mL}\left(\mathrm{NH}_{4}\right)_{2} \mathrm{MoS}_{4}$ (J\&K Chemical, Shanghai, China) aqueous solution $(5 \mathrm{mg} / \mathrm{mL})$ and magnetically stirred for $1.5 \mathrm{~h}$ (600 rounds/min). After sealed into a $100 \mathrm{~mL}$ stainless steel autoclave that lining with polyphenylene, the mixture was heated in an oven at $180{ }^{\circ} \mathrm{C}$ for $12 \mathrm{~h}$. Then, the product was thoroughly waterwashed for three times and centrifuged (8000 rounds/ min, $5 \mathrm{~min}$ ) to get LMM clay nanosheets. The $\mathrm{Mg}$ Al-LDH nanosheets preparation was similar to the synthesis of LMM nanosheets but without the addition of $\mathrm{Mn}\left(\mathrm{NO}_{3}\right)_{2} \cdot 4 \mathrm{H}_{2} \mathrm{O}$. The sediment was dissolved into $35 \mathrm{~mL}$ distilled water. The formed LMM clay nanosheets and Mg-Al-LDH nanosheets were lyophilized for future use. To prepare LMM@BSA clay nanosheets, $10 \mathrm{mg}$ freeze-dried powder of LMM was dispersed in $10 \mathrm{~mL}$ distilled water with $250 \mathrm{mg}$ BSA (Aladdin, Shanghai, China). The product then underwent an ultrasonic shattering $(500 \mathrm{~W}, 120 \mathrm{~min})$, centrifugation (13,000 rounds/min, $10 \mathrm{~min})$, and twice water-washed. The product was dissolved into $10 \mathrm{~mL}$ distilled water for further application. 


\section{Material characterization}

The surface morphology of LMM nanosheets was recorded using a scanning transmission electron microscopy (SEM, FEI Magellan 400). The microstructure of LMM@BSA clay nanosheets was observed by a transmission electron microscopy (TEM, FEI Tecnai G2 F20) and the thickness of LMM@BSA nanosheets was determined using an atomic force microscope (AFM, Bruker Dimension ICON). Before the SEM and TEM observation, LMM nanosheets was dissolve in water with a concentration of $100 \mu \mathrm{g} / \mathrm{mL}$. The distribution of $\mathrm{Al}, \mathrm{Mg}, \mathrm{Mo}$, $\mathrm{Mn}, \mathrm{O}$ and $\mathrm{S}$ in the LMM nanosheets was mapped with the Energy-dispersive Xray spectroscopy (as the accessory of TEM). The chemical nature of LMM material was characterized by X-ray photoelectron spectroscopy (XPS, Thermal Scientific ESCAlab250). The test results were calibrated by the $\mathrm{C} 1 \mathrm{~s}$ peak $(284.8 \mathrm{eV})$. X-ray diffraction (XRD, Rigaku D/max-2200 PC) system was used to assess the crystalline structures of LDH and LMM nanosheets [operation parameters: $\mathrm{Cu} \mathrm{K} \alpha$ radiation, the wavelength at $1.54 \AA$, scanning from $5^{\circ}$ to $70^{\circ}(2 \theta)$ ]. The scanning voltage and current was set as $40 \mathrm{kV}$ and $40 \mathrm{~mA}$, respectively. The chemical information of BSA and freeze-dried powder of LMM and LMM@BSA was determined by a Fourier Transform Infrared (FTIR) spectroscopy under the transmission mode in the wavelength range of 4000 to $500 \mathrm{~cm}^{-1}$ (Nicolet 7000-C spectrometer). The dynamic light scattering (DLS) diameters of LMM@BSA clay nanosheets in various solutions were also measured (Malvern Nano ZS90 Zetasizer Nano series). The mass ratio of surface-modified BSA was determined using thermogravimetric (TG209F1 system, NETZSCH Instruments Co., Ltd., Germany). Samples were heated from 50 to $900{ }^{\circ} \mathrm{C}$ with a heating rate of $20{ }^{\circ} \mathrm{C} / \mathrm{min}$ under air atmosphere. The UV-vis-NIR spectrometer (Lambda 25, Perkin Elmer, USA) was used to record the light absorption of nanosheets.

\section{In vitro photo-thermal performance}

The in vitro photo-thermal performance of the LMM@ BSA clay nanosheets was studied by continuously irradiating the nanosheets solution with $808 \mathrm{~nm}$ NIR laser (Shanghai Connet Fiber optics Company). The distance between the sample and the emitting end of NIR laser was $15 \mathrm{~cm}$. To study the influence of materials concentration on the photothermal conversion, a cell culture plate (96-well) of LMM@BSA clay nanosheets solutions at various concentrations (0 (distilled water, control), 50, 100, and $250 \mu \mathrm{g} / \mathrm{mL})$ was irradiated with NIR laser $(1.0 \mathrm{~W} /$ $\mathrm{cm}^{2}$ ) for a duration of $5 \mathrm{~min}$. To study the influence of power density on the photothermal conversion, LMM@ BSA clay nanosheets $(500 \mu \mathrm{g} / \mathrm{mL})$ were irradiated with
NIR laser $\left(0.2 \mathrm{~W} / \mathrm{cm}^{2}, 0.5 / \mathrm{cm}^{2}, 0.8 / \mathrm{cm}^{2}\right.$ and $\left.1.0 \mathrm{~W} / \mathrm{cm}^{2}\right)$ for a duration of $5 \mathrm{~min}$. The temperature changes $(\Delta T)$ and the related thermal images were recorded using a FLIR $^{\mathrm{TM}}$ E60 infrared camera. To prove the photo-thermal stability of the LMM@BSA clay nanosheets, $100 \mu \mathrm{L}$ solution was irradiated with NIR laser $(808 \mathrm{~nm})$, and its $\Delta T \mathrm{~s}$ in 10 cycles (laser on/off in turn) were plotted. The photo-thermal conversion efficiency ( $\eta$ ) of the LMM@ BSA clay nanosheets was ascertained with a modified Korgel's research method [41, 42], whose value could be calculated as follows:

$$
\eta=\frac{h S\left(T_{\max }-T_{\text {Surr }}\right)-Q_{\text {in,Surr }}}{I\left(1-10^{-A_{\lambda}}\right)} * 100 \% .
$$

In this formula, $S$ denotes the irradiated surface area of nanosheets. $h S$ could be determined by measuring the temperature dropping-speed since the beginning of the laser-off. $T_{\max }$ refers to the highest temperature of the nanosheets solution. $T_{\text {surr }}$ is the ambient temperature. $Q_{i n, s u r r}$ implies the heat transferred to the surrounding. I and $A(\lambda)$ respectively represent the laser power (in Watt) and the absorbance of the LMM@BSA clay nanosheets at $808 \mathrm{~nm}$.

\section{In vitro cytocompatibility}

At the incubation conditions $\left(37{ }^{\circ} \mathrm{C}\right.$ and $\left.5 \% \mathrm{CO}_{2}\right), \mathrm{L} 929$ cells (bought from Institute of Biochemistry and Cell Biology, the Chinese Academy of Science, Shanghai, China) were cultivated in DMEM which contained $100 \mu \mathrm{g} / \mathrm{mL}$ streptomycin, $100 \mathrm{U} / \mathrm{mL}$ penicillin and $10 \%$ fetal bovine serum. To assess the in vitro biocompatibility, the L929 cells were seeded into a cell culture plate (96-well, $8 \times 10^{3}$ cells/well). After cultured for $12 \mathrm{~h}$, the old medium was replaced with LMM@BSA clay nanosheets solution $(500,250,100,50$, and $0 \mu \mathrm{g} / \mathrm{mL}$ (control) in DMEM). After a 24-h incubation, the DMEM and materials were discarded. Cells were washed with PBS for 3 times and the metabolic activity and morphology of the L929 cells were evaluated by a cell counting kit-8 (CCK-8, Dojindo, Japan) and Live/Dead staining (LIVE/DEAD ${ }^{\mathrm{TM}}$ Cell Vitality Assay Kit, ThermoFisher Technologies, USA) according to the instructions. The live cells stain in green and the dead cells stain red. The stained cells were photographed using a Leica DM IL LED (Germany) inverted phase-contrast microscope.

Mice red blood cells (mRBCs) were centrifuged from the serum and washed with saline for 3 times. Thereafter, mRBCs were stored in PBS at $4{ }^{\circ} \mathrm{C}$. Upon experiment, $0.2 \mathrm{~mL} \mathrm{mRBC}$ suspension was evenly dispersed in three 1.5-mL Eppendorf tubes with $0.8 \mathrm{~mL}$ distilled water, saline, or LMM@BSA clay nanosheets (in saline) respectively. The final concentrations of 
the nanosheets are $50,100,200$, and $500 \mu \mathrm{g} / \mathrm{m}$. The mixtures were cultured for $2 \mathrm{~h}$ at $37{ }^{\circ} \mathrm{C}$ and centrifuged (5000 rounds/min, $3 \mathrm{~min}$ ). The absorbance of the supernatants at $541 \mathrm{~nm}$ was detected using the UV-vis-NIR spectrometer (Lambda 25, Perkin Elmer, USA). The hemolytic percentage (HP) was derived in the Eq. (2):

$$
\mathrm{HP}(\%)=\frac{\left(A_{t}-A_{n c}\right)}{\left(A_{p c}-A_{n c}\right)} .
$$

In this formula, $A_{n c}, A_{p c}$, and $A_{t}$ are absorbance values of PBS, water, and LMM@BSA clay nanosheets treated blood supernatant, respectively.

\section{Ce6 loading and singlet oxygen detection}

The LMM@BSA and Ce6 were magnetically stirred for $24 \mathrm{~h}$ at room temperature in dark. The final concentration of LMM@BSA was 100 or $500 \mu \mathrm{g} / \mathrm{mL}$, and the final Ce6 concentration was 10,50 , or $100 \mu \mathrm{g} / \mathrm{mL}$. Then, the mixture was centrifuged $(12,000$ rounds/ $\mathrm{min}, 10 \mathrm{~min}$ ) to separate the superfluous Ce6. The sediment was washed with distilled water for 3 times, and the loading efficiency of $\mathrm{Ce} 6$ could be determined according to the UV-vis-NIR spectra absorbance of these liquids, using the standard curve of Ce6 at $403 \mathrm{~nm}$. The loading efficiency was calculated in accordance with the formula (3):

$$
\text { Loading efficiency }(\%)=\frac{C_{0}-C_{s}}{C_{0}} * 100 \% .
$$

In this formula, $\mathrm{C}_{0}$ is the total concentration of Ce6, and $\mathrm{C}_{\mathrm{s}}$ is the Ce6 concentration in the supernatant.

A JPBJ-608 dissolved oxygen analyzer (Shanghai INESA Scientific Instrument Company) was used to quantize the dissolved oxygen (DO) content in LMM@BSA clay nanosheets solution. To this end, the electrode immersed in LMM@BSA clay nanosheets $(500 \mu \mathrm{g} / \mathrm{mL})$ solution with or without $\mathrm{H}_{2} \mathrm{O}_{2}(50 \mathrm{mM})$. These solutions were hand-shaken at $20-40 \mathrm{~cm} / \mathrm{s}$. The DO values were record by the analyzer at an interval of $30 \mathrm{~s}$ in a total duration of $10 \mathrm{~min}$. The singlet oxygen $\left({ }^{1} \mathrm{O}_{2}\right)$ produced by the Ce6 loaded nanosheets was probed using 1,3diphenylisobenzofuran (DPBF). In detail, $50 \mu \mathrm{L}$ DPBF (10 mM in ethanol) was added into the LMM@BSA/Ce6 aqeous solution $(2.95 \mathrm{~mL}$, $1 \mathrm{mg} / \mathrm{mL}$ ) with the absence or presence of $\mathrm{H}_{2} \mathrm{O}_{2}$ (final concentration $50 \mathrm{mM}$ ). The absorption spectra of the mixed solution were recored every $5 \mathrm{~min}$ during the $660 \mathrm{~nm}$ laser irradiation $\left(30 \mathrm{~min}, 0.1 \mathrm{~W} / \mathrm{cm}^{2}\right)$ using the UV-vis-NIR spectrometer (Lambda 25, Perkin Elmer, USA).

\section{In vitro tumor therapy}

\section{In vitro tumor PTT}

Human colorectal carcinoma (HT29) cells (obtained from Institute of Biochemistry and Cell Biology, the Chinese Academy of Science, Shanghai, China) were seeded in a 96-well plate $\left(8 \times 10^{3}\right.$ cells/well $)$ containing $100 \mu \mathrm{L}$ DMEM per well overnight. Next, the fresh medium with LMM@BSA clay nanosheets [0 (PBS), 50, 100, 250, and $500 \mu \mathrm{g} / \mathrm{mL}$ ] was substituted for the pure medium and the cells were cultured for $4 \mathrm{~h}$. Then, the cells were irradiated with $808 \mathrm{~nm}$ laser for $5 \mathrm{~min}$. To study the influence of power density on the cell viability, the cells cultured with $500 \mu \mathrm{g} / \mathrm{mL}$ LMM@BSA clay nanosheets were cultured for $4 \mathrm{~h}$ and then irradiated with $808 \mathrm{~nm}$ NIR laser $(0.2$, $0.5,0.8$, and $1.0 \mathrm{~W} / \mathrm{cm}^{2}$ ) for $5 \mathrm{~min}$. The metabolic activity and morphology of the L929 cells were evaluated by a cell counting kit-8 (CCK-8, Dojindo, Japan) and Live/ Dead staining.

\section{In vitro tumor PTT and PDT}

To study the irradiation time-dependent tumor PDT, cells (5 groups) were cultured with LMM@BSA/Ce6 nanosheets (LMM@BSA: $100 \mu \mathrm{g} / \mathrm{mL}$; Ce6: $10 \mu \mathrm{g} / \mathrm{mL}$ ) and cultured for $4 \mathrm{~h}$. Then, the alternated irradiation of $660 \mathrm{~nm}$ laser $\left(0.1 \mathrm{~W} / \mathrm{cm}^{2}\right)$ was applied to the cells (group I: without irradiation, control; group II: 1 min; group III: 2 min; group IV: 3 min; group V: $5 \mathrm{~min}$ ). To study the combined tumor PTT and PDT, cells were cultured with LMM@BSA clay nanosheets (group I and II, $100 \mu \mathrm{g} / \mathrm{mL}$ ) or LMM@BSA/Ce6 (group III and IV, 100 g/mL LMM@ BSA, $10 \mu \mathrm{g} / \mathrm{mL}$ Ce6). Then, the alternated irradiation of $660 \mathrm{~nm}$ laser $\left(0.1 \mathrm{~W} / \mathrm{cm}^{2}\right)$ and $808 \mathrm{~nm}$ laser $\left(1.0 \mathrm{~W} / \mathrm{cm}^{2}\right)$ was applied to the cells (group I: without irradiation; group II: $808 \mathrm{~nm}, 5 \mathrm{~min}$; group III: $606 \mathrm{~nm}, 5 \mathrm{~min}$; group IV: $606 \mathrm{~nm}, 5 \mathrm{~min}$, and $808 \mathrm{~nm}, 5 \mathrm{~min}$ ). The metabolic activity and morphology of the L929 cells were evaluated by a cell counting kit-8 (CCK-8, Dojindo, Japan) and Live/Dead staining.

\section{In vivo biocompatibility}

The in vivo studies were performed in Changhai Hospital, Second Military Medical University. The animal-handling was in accordance with the policies of the National Ministry of Health. KM mice (SPF level, Shanghai Slac Laboratory Animal Center, China) were intravenously (I.V.) injected with $200 \mu \mathrm{L}$ LMM@BSA clay nanosheets solution ( $3 \mathrm{mg} / \mathrm{mL}$, in saline). Another group injected with $200 \mu \mathrm{L}$ saline was set as control. These mice were euthanized on the 1st day, 7th day, and 14th day. The body weight of KM mice was about $20 \mathrm{~g}$. Therefore the injected dosage of LMM@BSA clay nanosheets to mice could be determined as about $30 \mathrm{mg} / \mathrm{kg}$. Major organs 
(kidney, lung, spleen, liver, and heart) of these mice were weighed and aqua regia was used to thoroughly digest these weighed organs for 3 days to quantify their respective contents of $\mathrm{Mn}$ ions with an Agilent ICPOES (700 Series). The KM mice body weights were also monitored during the experiment. Standard hematoxylin-eosin (H\&E) dyeing was introduced to assess the in vivo biosafety of the LMM@BSA clay nanosheets with the help of a Leica DM IL LED inverted phase-contrast microscope.

For the in vivo hemocompatibility assessment, the routine blood test (using Sysmex XS-800i automated hematology analyzer) and serum biochemistry test (using Beckman Coulter Unicel DxC 800 automatic biochemical analyzer) were performed as follows: KM mice I.V. administered with $200 \mu \mathrm{L}$ saline (set as control) or nanosheets solution $(3 \mathrm{mg} / \mathrm{mL})$ were anesthetized by puncturing the heart for blood-drawing on the 1st, 7th, and 14th day post-injection.

\section{In vitro and in vivo MR imaging}

The Mn content in $20 \mathrm{mg}$ LMM@BSA clay nanosheets (digested in aqua regia) was firstly ascertained by an Inductive Coupled Plasma Emission Spectrometer (ICP). LMM@BSA clay nanosheets solutions at a gradient $\mathrm{Mn}$ concentration $(1.0 \mathrm{~mL}, \mathrm{Mn}$ concentration: $0.2 \mathrm{mg} / \mathrm{mL}$, $0.5 \mathrm{mg} / \mathrm{mL}$ and $1.0 \mathrm{mg} / \mathrm{mL}$ ) in three solvents, namely distilled water, $\mathrm{GSH}$, and citric acid buffer $(\mathrm{pH}=5.0)$ and incubated for $2 \mathrm{~h}$. Then, $\mathrm{T}_{1}$-weighed MR imaging was finished on an MR imaging system (GE Signa 3.0 T, imaging parameters: $\mathrm{TR}=600 \mathrm{~ms}$; $\mathrm{TE}=$ Min Full; bandwidth $=15.63 \mathrm{kHz}$; and slice thickness $=3 \mathrm{~mm}$ ).

The nude mice (Shanghai Slac Laboratory Animal Center, Shanghai, China) were subcutaneously injected with $150 \mu \mathrm{L}$ serum-free DMEM containing $1 \times 10^{7}$ HT29 cells on their backs for the construction of tumor models. When the tumor grew into $\sim 0.5 \mathrm{~cm}^{3}$ after approximately 2 weeks of feeding, the tumor-bearing mice were intratumorally (I.T.) or I.V. injected with the LMM@BSA clay nanosheets $(1 \mathrm{mg} / \mathrm{mL}$ in saline). These mice were anesthetized and placed in a home-made plate immediately after the I.T. materials injection or $12 \mathrm{~h}$ after the I.V. materials injection for the in vivo imaging (imaging parameters: $\mathrm{TR}=400 \mathrm{~ms}$; $\mathrm{TE}=8.9 \mathrm{~ms}$; Fov $=6 \times 6 \mathrm{~cm}$; and slice thickness $=2 \mathrm{~mm}$ ). The relative brightness intensity (RBI) was calculated based on the Eq. (4):

$$
\mathrm{RBI}=\frac{\mathrm{BI}_{\mathrm{x}}}{\mathrm{BI}_{\mathrm{o}}}
$$

In this formula, $\mathrm{BI}_{\mathrm{x}}$ and $\mathrm{BI}_{\mathrm{o}}$ represent the brightness intensity of the experimental and control groups in the MR region of interest (area $=5 \mathrm{~mm}^{2}$ ), respectively.

\section{In vivo tumor therapy}

Tumor-bearing mice were randomized into five groups $(\mathrm{n}=3)$. These mice were I.V. injected with saline (group I, $200 \mu \mathrm{L}$ ), or $200 \mu \mathrm{L}$ LMM@BSA/Ce6 (group II - IV, $1 \mathrm{mg} / \mathrm{mL}$ in saline). Members in group $\mathrm{V}$ were I.T. injected with $20 \mu \mathrm{L}$ LMM@BSA/Ce6 (in saline). After $12 \mathrm{~h}$, the mice in the group II and III were received the $808 \mathrm{~nm}$ (group II, $1.0 \mathrm{~W} / \mathrm{cm}^{2}, 5 \mathrm{~min}$ ) and $660 \mathrm{~nm}$ (group III, $0.1 \mathrm{~W} / \mathrm{cm}^{2}, 5 \mathrm{~min}$ ) NIR laser irradiation respectively. The mice in group IV and V were successively irradiated with $660 \mathrm{~nm}\left(0.1 \mathrm{~W} / \mathrm{cm}^{2}\right)$ and $808 \mathrm{~nm}$ $\left(1.0 \mathrm{~W} / \mathrm{cm}^{2}\right)$ laser for $5 \mathrm{~min}$. The $\Delta \mathrm{Ts}$ of tumor and the thermal images during treatment were recorded using a FLIR ${ }^{\mathrm{TM}}$ E60 camera. At different time points, relative tumor volume (denoted as $V / V_{0}, V_{0}$ and $V$ represent the real-time and initial tumor volume, respectively) and the appearance of each tumor-bearing mouse was recorded. The power density of $808 \mathrm{~nm}$ laser is $1.0 \mathrm{~W} /$ $\mathrm{cm}^{2}$ and the power density of $660 \mathrm{~nm}$ laser is $0.1 \mathrm{~W} /$ $\mathrm{cm}^{2}$ in this study.

\section{Drug loading and release}

To load DOX, a stock solution of DOX $(10 \mathrm{mg} / \mathrm{mL}$, $20 \mu \mathrm{L}$ ) was added into the LMM@BSA clay nanosheets solution $(1 \mathrm{mg} / \mathrm{mL})$ under room temperature and stirred for $24 \mathrm{~h}$ in the dark. The product was purified by centrifugation (12,000 rounds/min, $10 \mathrm{~min}$ ) and rinsed with water for 3 times. The absorbance of the collected supernatant at $480 \mathrm{~nm}$ was determined by UV-vis-NIR spectroscopy to calculate the DOX loading quantity according to the concentration-absorbance standard curve of DOX at the same wavelength.

The drug release from the LMM@BSA/DOX nanosheets was studied at different $\mathrm{pH}$ values and temperatures. In detail, LMM@BSA/DOX solutions were placed in vials containing $5 \mathrm{~mL}$ buffer with different $\mathrm{pH}$ values [PBS $(\mathrm{pH}=7.4)$ or citrate buffer solution $(\mathrm{pH}=6.0)]$ and incubated at $54{ }^{\circ} \mathrm{C}$ or $37{ }^{\circ} \mathrm{C}$, respectively. At pre-designed time points, $1 \mathrm{~mL}$ buffer containing the released DOX was taken out and its absorbance at $480 \mathrm{~nm}$ was monitored for calculating the real-time released DOX amount. Finally, $1 \mathrm{~mL}$ fresh buffer was supplanted.

\section{Statistical analysis}

The one way ANOVA statistical analysis was chosen to determine the significance of data, where 0.05 was appointed as the threshold $\left[\left(^{*}\right) \mathrm{p}<0.05,\left({ }^{* * *}\right) \mathrm{p}<0.01\right.$, $(* * *) \mathrm{p}<0.001]$. Unless specified, the sample size is three $(\mathrm{n}=3)$ in this study. 


\section{Results and discussions}

\section{Materials synthesis and characterization}

Unlike the traditional co-precipitation route which involves the two-step nucleation and sediment ageing [43], the LDH-based clay nanosheets, namely the LMM, was synthesized via hydrothermally treating the mixture solution of $\mathrm{NaOH},\left(\mathrm{NH}_{4}\right)_{2} \mathrm{MoS}_{4}, \mathrm{Mn}\left(\mathrm{NO}_{3}\right)_{2} \cdot 4 \mathrm{H}_{2} \mathrm{O}$, $\mathrm{Mg}\left(\mathrm{NO}_{3}\right)_{2} \cdot 6 \mathrm{H}_{2} \mathrm{O}$ and $\mathrm{Al}\left(\mathrm{NO}_{3}\right)_{3} \cdot 9 \mathrm{H}_{2} \mathrm{O}$. During the hydrothermal synthesis, $\mathrm{Mn}\left(\mathrm{NO}_{3}\right)_{2} \cdot 4 \mathrm{H}_{2} \mathrm{O}, \mathrm{Mg}\left(\mathrm{NO}_{3}\right)_{2} \cdot 6 \mathrm{H}_{2} \mathrm{O}$ and $\mathrm{Al}\left(\mathrm{NO}_{3}\right)_{3} \cdot 9 \mathrm{H}_{2} \mathrm{O}$ were transformed into $\mathrm{Mg}-\mathrm{Mn}-\mathrm{Al}$ $\mathrm{LDH}$, and $\left(\mathrm{NH}_{4}\right)_{2} \mathrm{MoS}_{4}$ was transformed into $\mathrm{MoS}_{2}$. The LMM was sonicated in BSA soluton for BSA coating to gain colloidal stability in physiological conditions. The as-prepared LMM@BSA clay nanosheets were further used to load Ce6, which could generate the cytoxic ROS (i.e., ${ }^{1} \mathrm{O}_{2}$ ) upon the $660 \mathrm{~nm}$ laser irradiation, for the MR imaging-guided photo-therapy of the tumor (Scheme 1). It could be easily observed from the SEM that the as-prepared product presents a 2D structure (Fig. 1a, b). After the sonication in BSA solution, LMM@BSA multi-layers with a thickness of $\sim 5.5 \mathrm{~nm}$ was obtained (Additional file 1: Fig. S1a, b). The element mapping (Fig. 1d-i) further verifies the even coexistence of $\mathrm{Al}, \mathrm{Mg}, \mathrm{Mo}, \mathrm{Mn}, \mathrm{O}$, and $S$ in the LMM@BSA clay nanosheets.

XPS analysis was introduced to research the valence state of various elements in the nanosheets. The peaks belonging to $\mathrm{Mo}^{4+} 3 \mathrm{~d}^{5 / 2}$ (at $228.6 \mathrm{eV}$ ), $\mathrm{Mo}^{6+} 3 \mathrm{~d}^{5 / 2}$ $(232.0 \mathrm{eV})$ and $3 \mathrm{~d}^{3 / 2}(235.9 \mathrm{eV})$ (Additional file 1: Fig. $\mathrm{S} 2 \mathrm{a})$; peaks at $74.7 \mathrm{eV}$ and $1304.1 \mathrm{eV}$ were ascribed to $\mathrm{Al}$ $2 \mathrm{p}^{3 / 2}$ and $\mathrm{Mg} 1 \mathrm{~s}$ respectively were also detected in the XPS spectrum of Mo element (Additional file 1: Fig. S2b, c). The peak of $\mathrm{S}^{2-}$ at $162.18 \mathrm{eV}\left(\mathrm{S} 2 \mathrm{p}^{3 / 2}\right)$ was observed as well (Additional file 1: Fig. S2d), confirming that the nanosheets are composed of $\mathrm{MoS}_{2}$. In addition, the peaks at $641.2 \mathrm{eV}, 653.4 \mathrm{eV}, 653.8 \mathrm{eV}$, and $642.5 \mathrm{eV}$ represent $\mathrm{Mn}^{3+} 2 \mathrm{p}^{3 / 2}, \mathrm{Mn}^{2+} 2 \mathrm{p}^{1 / 2}, \mathrm{Mn}^{3+} 2 \mathrm{p}^{1 / 2}$, and $\mathrm{Mn}^{2+} 2 \mathrm{p}^{3 / 2}$ (Fig. 2a), respectively, indicating that the valences of $\mathrm{Mn}$ are $\mathrm{Mn}^{3+}$ and $\mathrm{Mn}^{2+}$. The XPS spectrum of Mn was

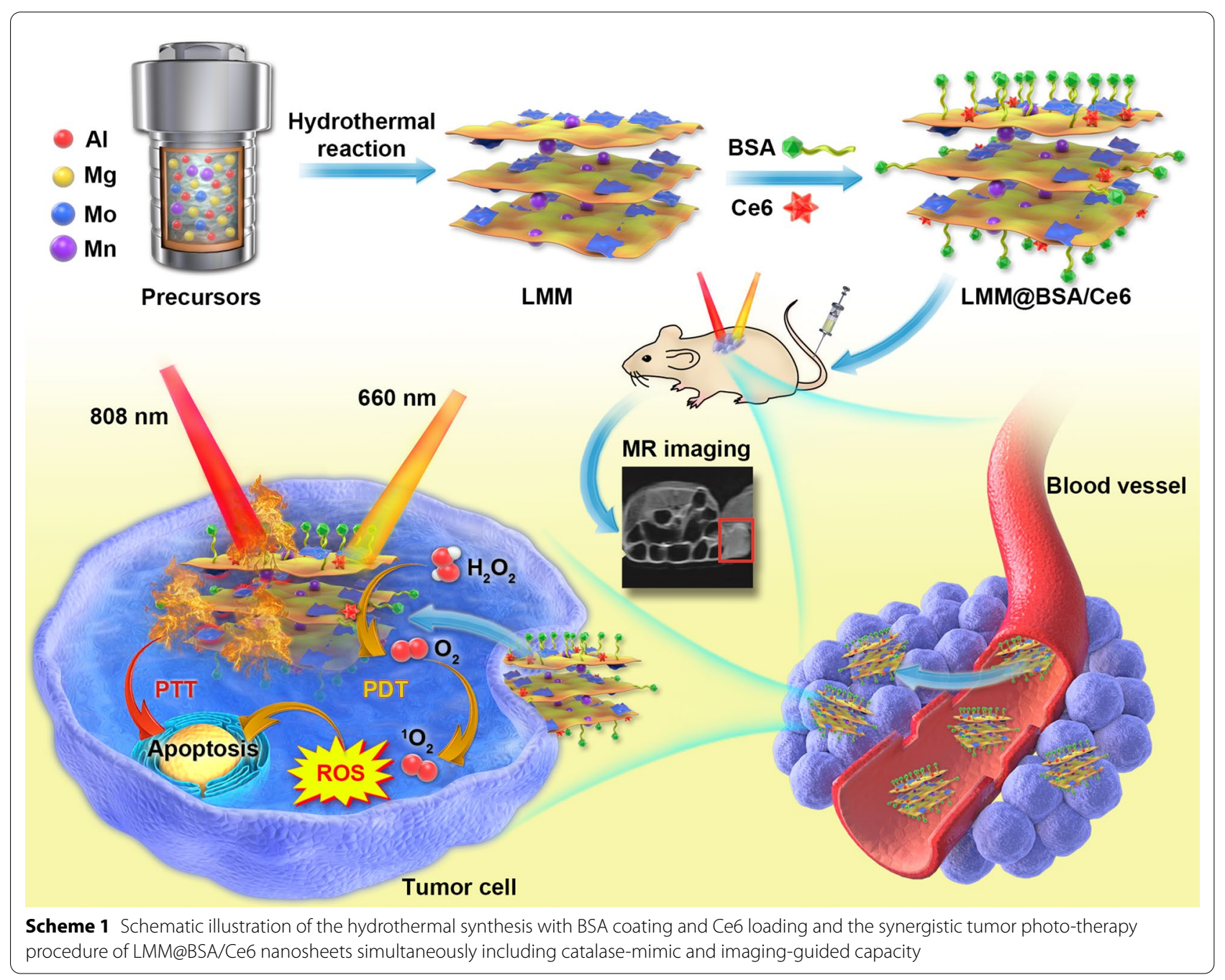



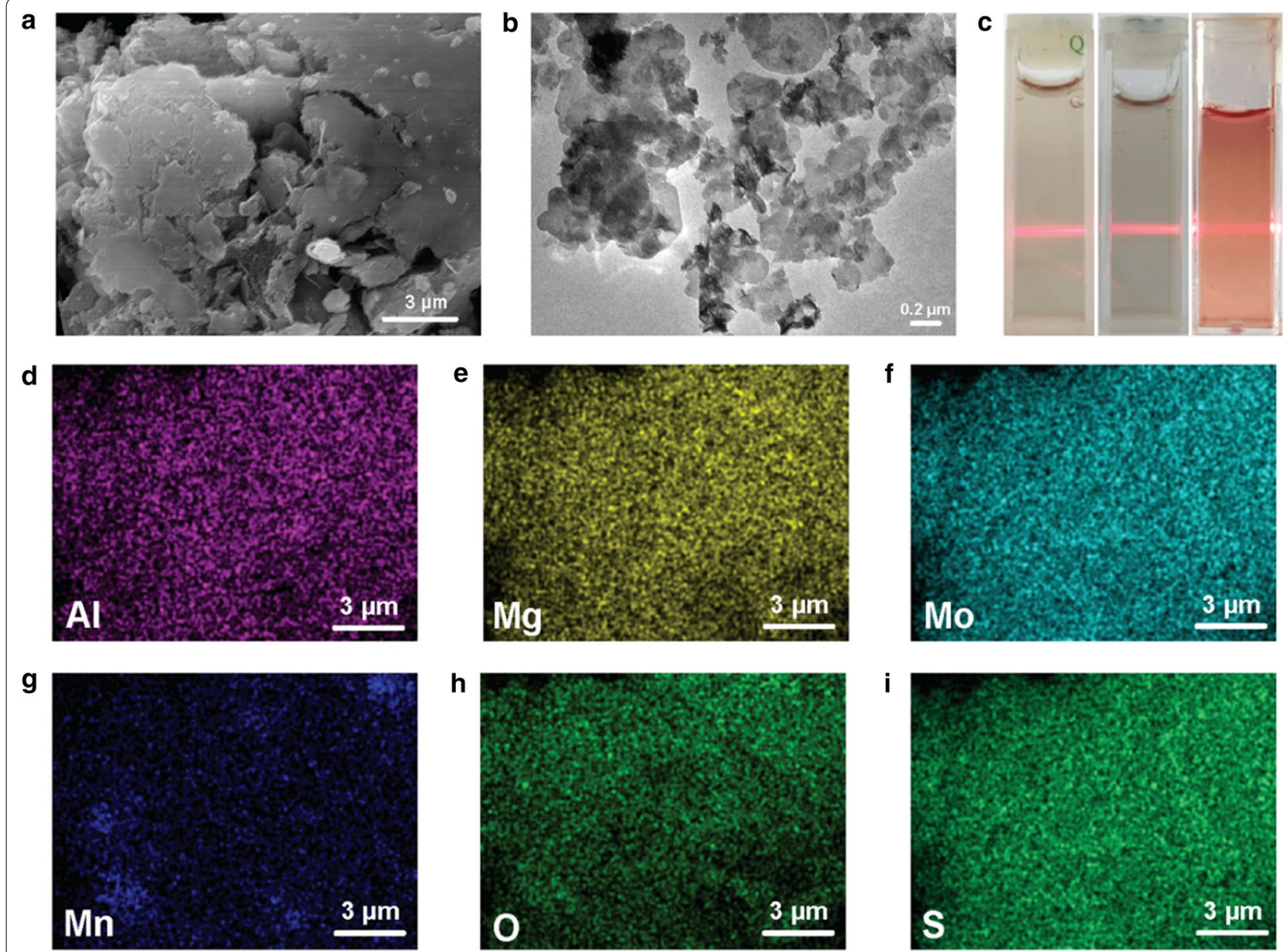

Fig. 1 a SEM of LMM nanosheets; b TEM of LMM@BSA nanosheets; c photographic image of typical Tyndall phenomenon of LMM@BSA clay nanosheets in water (left), saline (middle), and DMEM (right); $\mathbf{d}-\mathbf{i}$ Al, Mg, Mo, Mn, O and S elemental distribution mappings of LMM nanosheets

fitted according to literature and the atom ratio of $\mathrm{Mn}^{3+}$ and $\mathrm{Mn}^{2+}$ was evaluated to be 50.7:49.3 [44]. The structural nature of LMM nanosheets was then studied using XRD (Fig. 2b). Compared with Mg-Al-LDH, the typical (003), (006), (012) and (110) peaks at $11.70^{\circ}, 23.54^{\circ}, 33.4^{\circ}$, 60.23 (JCPDS: 14-0191) were weakened after doping with $\mathrm{MoS}_{2}$ (red line: $\mathrm{LDH}-\mathrm{MoS}_{2}$ ) and even disappeared after further doping with manganese (blue line: LMM). Besides, the (002) peak of $\mathrm{MoS}_{2}$ (JCPDS: 75-1539, red line: $\mathrm{LDH}-\mathrm{MoS}_{2}$ ) was also weakened after doping with manganese (blue line: LMM), implying that the doping of Mo and Mn has restricted the growth of the crystalline of Mg-Al-LDH.

FTIR was used to confirm the successful BSA coating (Fig. 2c). The peaks at $3320 \mathrm{~cm}^{-1}$ and $2950 \mathrm{~cm}^{-1}$ represented the asymmetry elastic of $-\mathrm{NH}_{2}$ and $-\mathrm{CH}_{3}$ of BSA. Peaks belonging to amide III, II, and I at $1390 \mathrm{~cm}^{-1}$, $1540 \mathrm{~cm}^{-1}$, and $1640 \mathrm{~cm}^{-1}$ could be found in the curve of BSA and LMM@BSA clay nanosheets, revealing the successful coating of BSA. To quantify the amount of surface-coated BSA, LMM, BSA, and LMM@BSA clay nanosheets were programmatically heated to $900{ }^{\circ} \mathrm{C}$ in air, which confirms that the mass ratio of surfacecoated BSA was approximately $56.4 \%$ (Fig. 2d). The size of LMM@BSA clay nanosheets in DMEM was $147 \mathrm{~nm}$, and the size fluctuation of DLS during $24 \mathrm{~h}$ was ignorable (Additional file 1: Fig. S3). Moreover, the LMM@BSA clay nanosheets could be well-dispersed in water, PBS, and DMEM and showed the noticeable Tyndall effect (Fig. 1c), indicating that the modified BSA molecules endow the nanosheets with excellent colloidal stability in certain circumstances.

\section{In vitro photo-thermal performance}

In line with the $\mathrm{MoS}_{2}[45,46]$, the LMM@BSA clay nanosheets demonstrate apparent light absorption that 

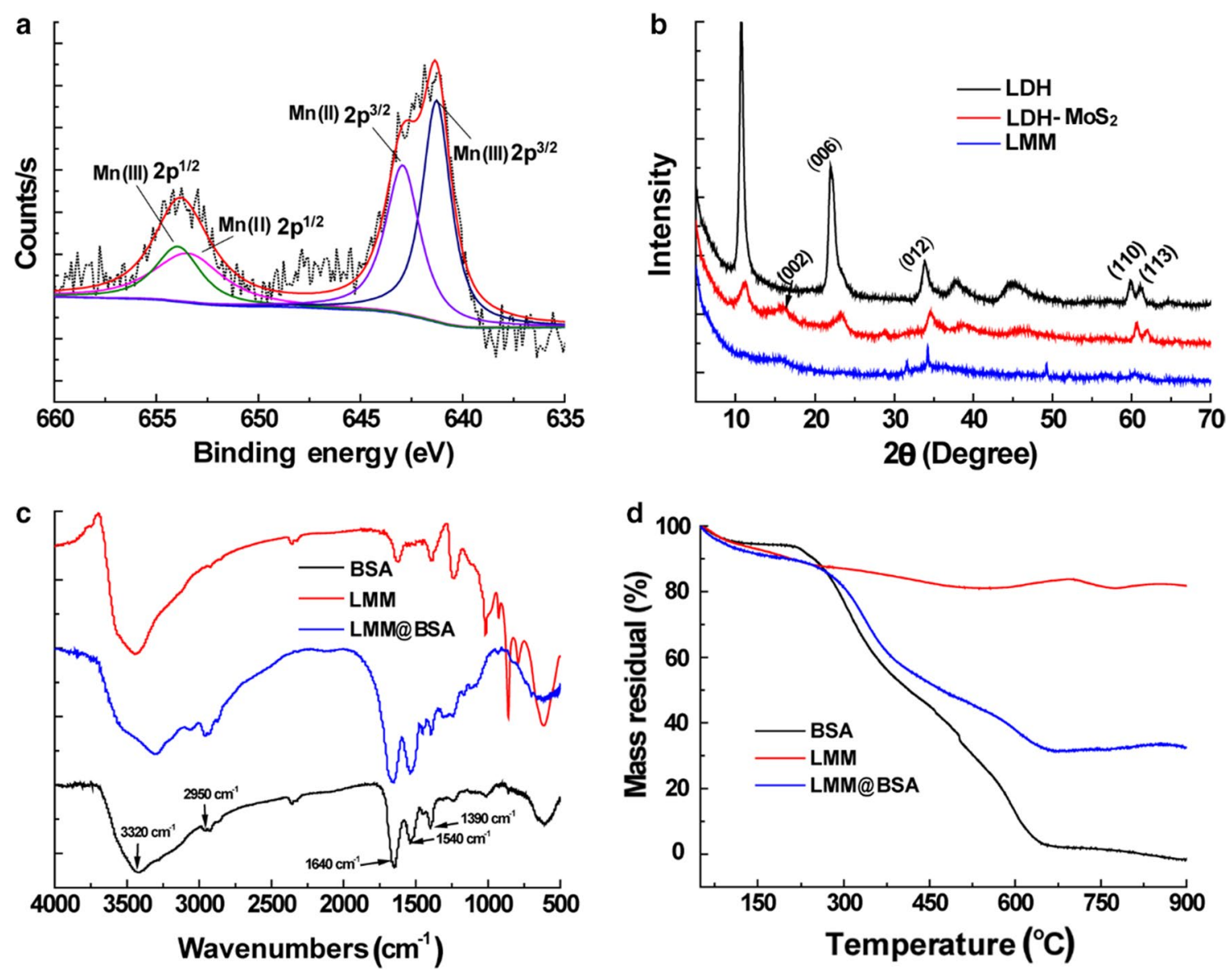

Fig. 2 a XPS spectrum of Mn 2p; b XRD patterns of LDH, LDH-MoS 2 , and LMM nanosheets; $\mathbf{c}$ FTIR spectra of LDH, LMM, and LMM@BSA nanosheets; d TG curves of LDH, LMM and LMM@BSA nanosheets

is closely related to their concentration within wavelength from 400 to $1100 \mathrm{~nm}$ (Fig. 3a). Setting the experimental device according to Fig. $3 \mathrm{~b}$ and under laser irradiation $\left(1.0 \mathrm{~W} / \mathrm{cm}^{2}, 5 \mathrm{~min}\right)$, the solution temperatures swiftly increased by $13{ }^{\circ} \mathrm{C}, 21^{\circ} \mathrm{C}$, and $33{ }^{\circ} \mathrm{C}$ corresponding to their concentrations at $50 \mu \mathrm{g} / \mathrm{mL}, 100 \mu \mathrm{g} /$ $\mathrm{mL}$, and $250 \mu \mathrm{g} / \mathrm{mL}$, respectively. However, under the same circumstance, the distilled water merely increased by $6.5^{\circ} \mathrm{C}$ (Fig. 3c). When irradiating the LMM@BSA clay nanosheets $(500 \mu \mathrm{g} / \mathrm{mL})$ with varied laser power density, the temperatures increased by $44{ }^{\circ} \mathrm{C}, 34{ }^{\circ} \mathrm{C}, 22^{\circ} \mathrm{C}$ and $9{ }^{\circ} \mathrm{C}$ upon laser powered at $1.0 \mathrm{~W} / \mathrm{cm}^{2}, 0.8 \mathrm{~W} / \mathrm{cm}^{2}, 0.5 \mathrm{~W} / \mathrm{cm}^{2}$ and $0.2 \mathrm{~W} / \mathrm{cm}^{2}$, respectively (Fig. 3e). The related thermal picture captured by the FLIR ${ }^{\mathrm{TM}}$ camera further reinforced the relationship of photo-thermal performance with irradiation time, power density and material concentration (Fig. 3d, f). The photo-thermal efficiency of the LMM@ BSA clay nanosheets was figured at $31.6 \%$ (Fig. 3g, h), which is higher than $\mathrm{MoS}_{2}$ nanospheres [16] and other kinds of $\mathrm{MoS}_{2}$ based composites (like $\mathrm{MoS}_{2} @ \mathrm{Fe}_{3} \mathrm{O}_{4}$-ICG/ $\mathrm{Pt}(\mathrm{IV})$ nanoflowers) [15]. Moreover, negligible maximum temperature changes after being irradiated by $808 \mathrm{~nm}$ laser for 10 cycles were observed, indicating the desirable thermal stability of LMM@BSA clay nanosheets (Fig. 3i). Given the outstanding photo-thermal conversion efficiency and thermal durability, it was anticipated that LMM@BSA clay nanosheets are suitable for the tumor hyperthermia treatment.

\section{In vitro compatibility}

The appraisal of in vitro cytotoxicity of LMM@BSA clay nanosheets is fundamental for its biomedical applications. The viability of L929 cells that were cultured with LMM@BSA clay nanosheets for $24 \mathrm{~h}$ remained higher than $90 \%(0-500 \mu \mathrm{g} / \mathrm{mL}$, Additional file 1: Fig. S4a), with similar morphology to those treated with saline (control, Additional file 1: Fig. S5a, b). Further, calcein-AM/ PI study suggests that the Live/Dead cells staining results were in accordance with CCK- 8 assay and the morphology observation evidently proved that the nanosheets would not destruct the integrity of cell membrane in the 

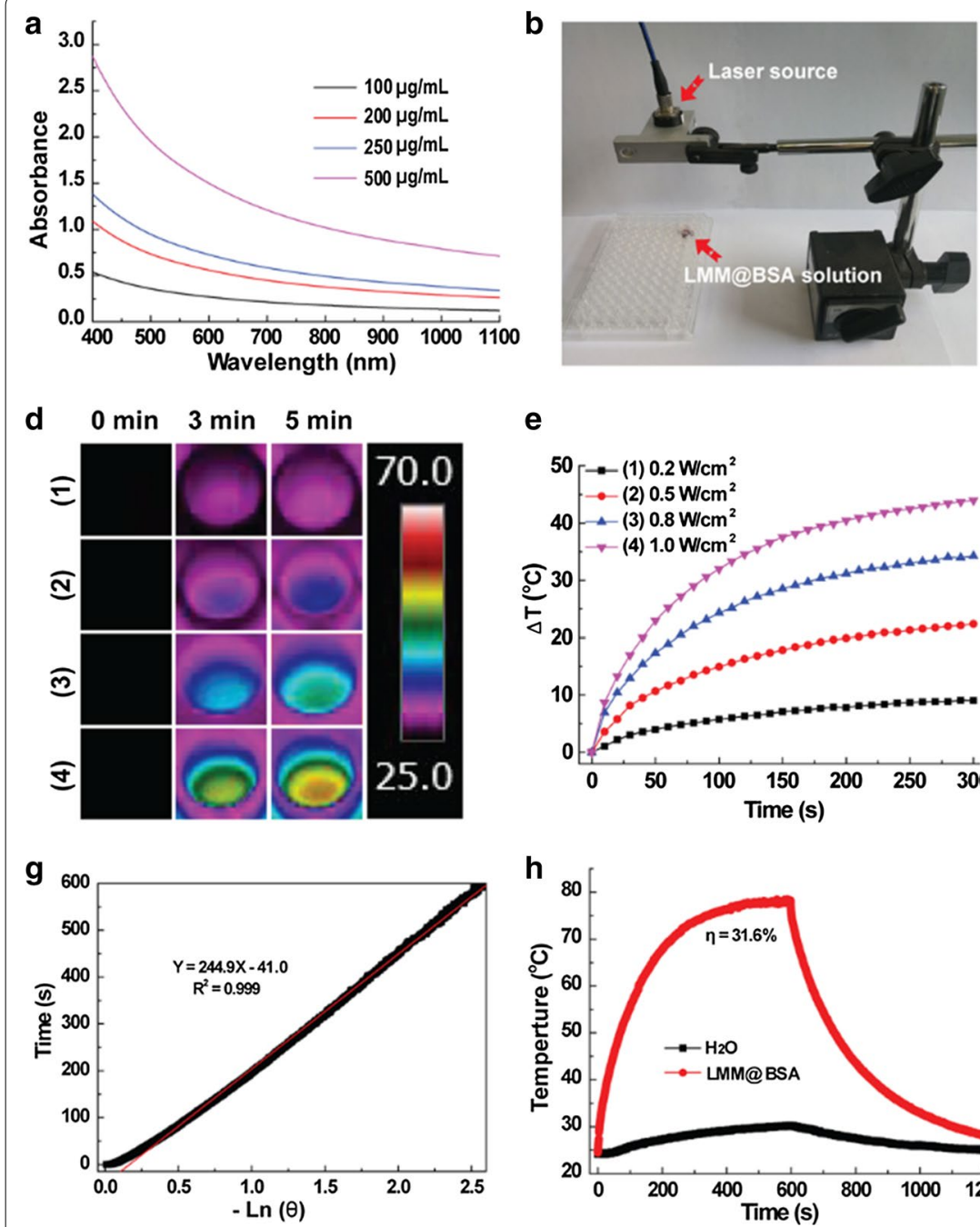

e

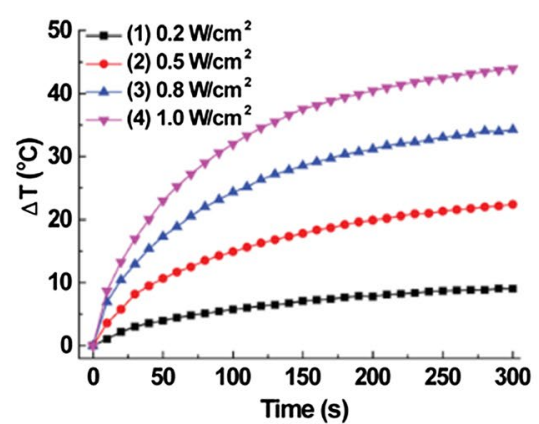

$\mathbf{h}$

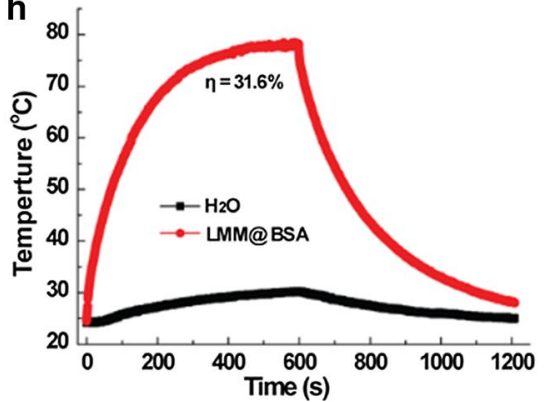

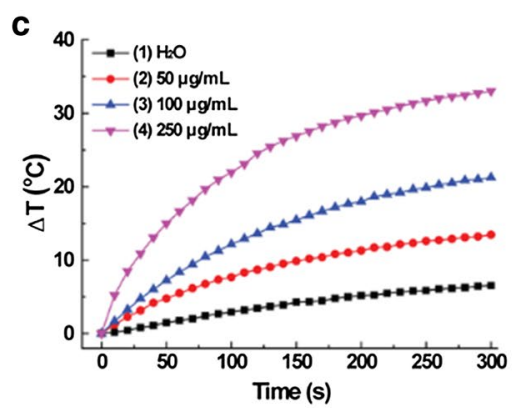

f

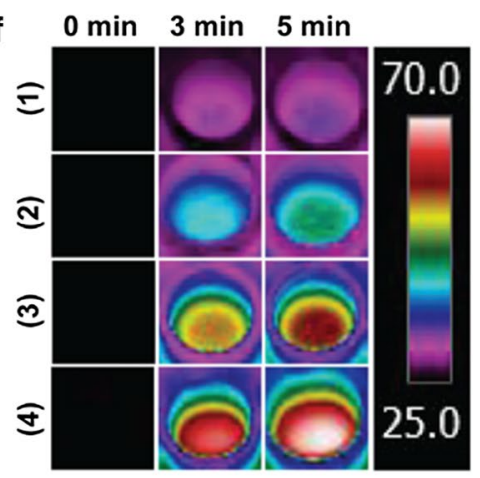

i

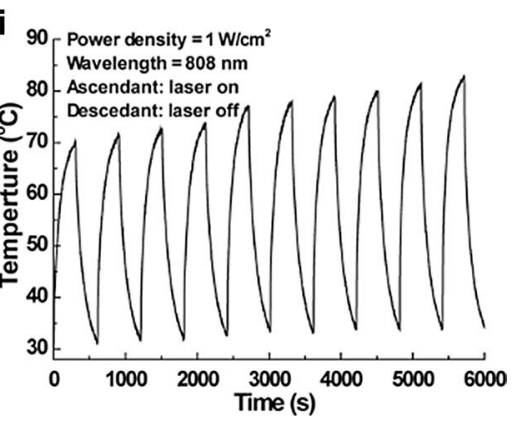

Fig. 3 a Light absorption of LMM@BSA clay nanosheets solution; $\mathbf{b}$ the photograph of the experimental appliance; $\mathbf{c}$ distilled water and concentration-dependent temperature profiles of LMM@BSA clay nanosheets (NIR laser: $1 \mathrm{~W} / \mathrm{cm}^{2}$ ); $\mathbf{d}$ corresponding thermal imaging of $\mathbf{c}$; e power density-dependent temperature profiles of LMM@BSA clay nanosheets solution; $\mathbf{f}$ corresponding thermal imaging of $\mathbf{e} ; \mathbf{g}$ time constant for heat transfer of LMM@BSA clay nanosheets; $\boldsymbol{h}$ steady-state heating curve of LMM@BSA clay nanosheets and distilled water and $\mathbf{i}$ recycling heating profiles of LMM@BSA clay nanosheets. The unit of bar in $\mathbf{d}$ and $\mathbf{f}$ is ${ }^{\circ} \mathrm{C}$

experimental concentration range (Additional file 1: Fig. S4b-f).

To further prove the hemocompatibility of LMM@ BSA, the hemolytic assay was carried out. As calculated, the HPs of experimental samples turned out to be lower than $2 \%$ under nanosheets concentration of $0-500 \mu \mathrm{g} /$ $\mathrm{mL}$ (Additional file 1: Fig. S6), implying the excellent hemocompatibility of LMM@BSA clay nanosheets within the experimental dosage.

\section{Ce6 loading and detection of ${ }^{1} \mathrm{O}_{2}$}

The interlayer space and the surface of the LMM@ BSA clay nanosheets could contribute to its physical adsorption of drugs or photosensitizers. In this study, the photosensitizer agent, namely $\mathrm{Ce} 6$, was mixed with LMM@BSA, after which a characteristic peak at $403 \mathrm{~nm}$ belonging to Ce6 was successfully detected in the UVvis-NIR spectrum of the centrifugal product (Additional file 1: Fig. S7). This indicated that the Ce6 was successfully loaded on LMM@BSA clay nanosheets. Owing to the increased loading sites, the loading efficiency of $\mathrm{Ce} 6$ was found to grow with the increasing-concentration of LMM@BSA clay nanosheets. Besides, the increasing of Ce6 concentration could also raise the Ce6 loading efficiency, and a high loading efficiency of $89.37 \pm 3.92 \%$ was obtained when the LMM@BSA and Ce6 concentrations 

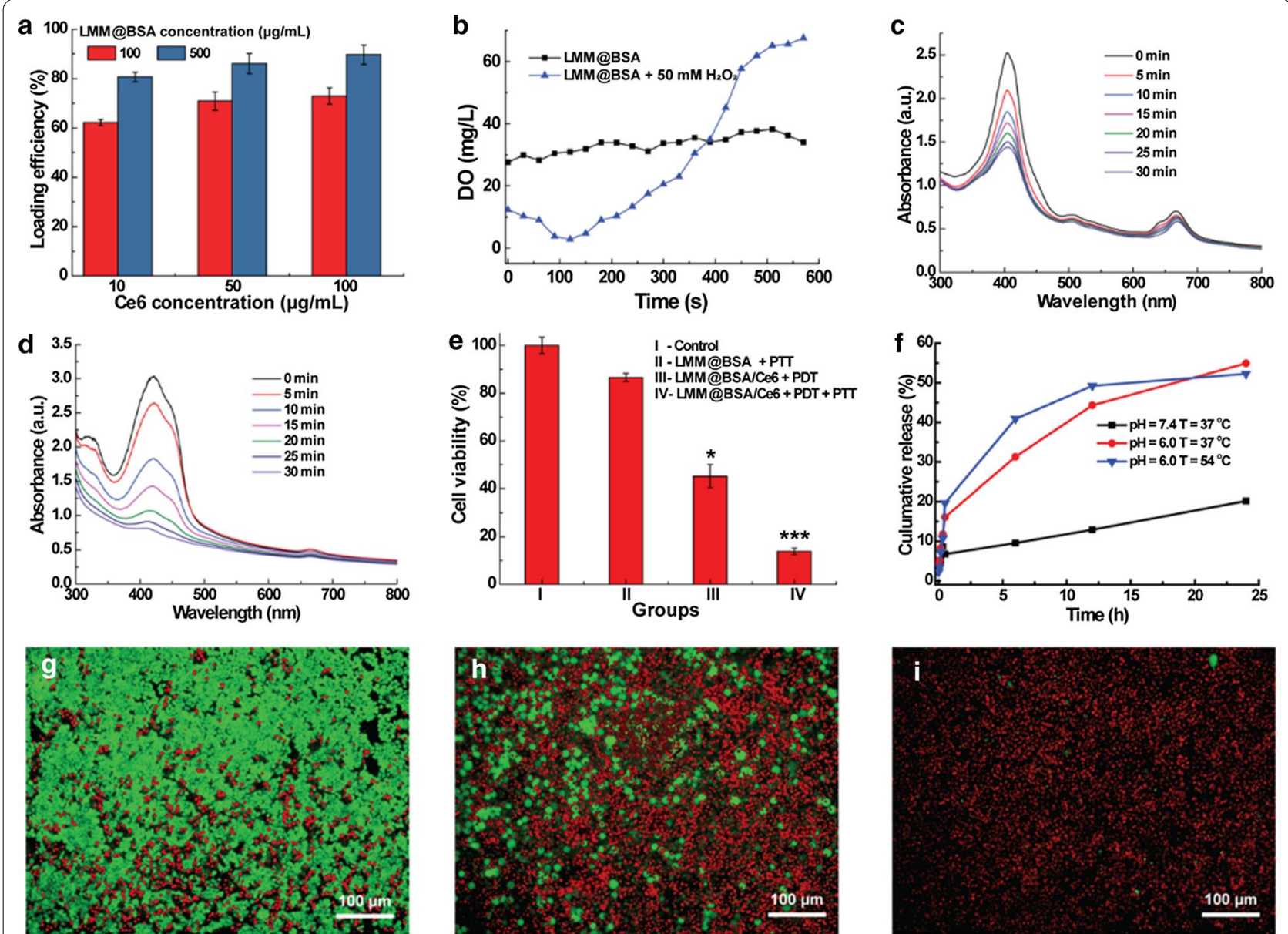

Fig. 4 a The Ce6 loading efficiency of LMM@BSA clay nanosheets with different concentrations; $\mathbf{b}$ the DO content (mg/L) of dissolved oxygen in LMM@BSA and LMM@BSA $+\mathrm{H}_{2} \mathrm{O}_{2}$ solution; $\mathbf{c}$, $\mathbf{d}$ absorption spectrum changes of DPBF under $660 \mathrm{~nm}$ laser irradiation with LMM@BSA/Ce6 nanosheets $\mathbf{c}$ in the absence and $\mathbf{d}$ presence of $\mathrm{H}_{2} \mathrm{O}_{2}(10 \mathrm{mM})$; e viability profile of $\mathrm{HT} 29$ cells after different treatments; $\mathbf{f}$ in vitro cumulative release profiles of DOX from LMM@BSA/DOX nanosheets under different $\mathrm{pH}$ and temperature; $\mathbf{g}-\mathbf{i}$ the calcein-AM/PI dyeing morphology of HT29 cells corresponding to e; $\mathbf{g}$ LMM@BSA + PTT; $\mathbf{h}$ LMM@BSA/Ce6 + PDT; i LMM@BSA/Ce6 + PDT+PTT

were $500 \mu \mathrm{g} / \mathrm{mL}$ and $100 \mu \mathrm{g} / \mathrm{mL}$, respectively (Fig. 4a). The loading percentage of Ce6 was calculated as about $15 \%$ when dividing the loaded amount of Ce6 with the total amount of LMM@BSA and Ce6. To confirm the catalytic efficiency of LMM@BSA, the DO content in LMM@BSA solution with and without the addition of $\mathrm{H}_{2} \mathrm{O}_{2}$ was compared. The introduction of $\mathrm{H}_{2} \mathrm{O}_{2}$ led to an increase in the DO content of the LMM@BSA solution (Fig. 4b), implying that the $\mathrm{H}_{2} \mathrm{O}_{2}$ has been transformed into $\mathrm{O}_{2}$ under the catalysis of LMM@BSA. It was worth noting that the obvious lower starting value in the DO content might be corresponding to the $\mathrm{H}_{2} \mathrm{O}_{2}$-induced degradation of nanosheets, which consumed the oxygen to some extent.
To certificate that LMM@BSA could enhance the ROS production of $\mathrm{Ce} 6$ under the irradiation of $660 \mathrm{~nm}$ laser, the ${ }^{1} \mathrm{O}_{2}$ production of LMM@BSA/Ce6 was studied (Fig. 4c, d). The structure of DBPF alters quickly upon strong oxidants such as ROS [17], leading to the apparent decrease of light absorption at $410 \mathrm{~nm}$. Therefore, it was applied to indicate the emergence of ${ }^{1} \mathrm{O}_{2}$. Upon the irradiation with $660 \mathrm{~nm}$ laser, the absorption peaks of DPBF at $410 \mathrm{~nm}$ were weakened, implying the continuous generation of ${ }^{1} \mathrm{O}_{2}$. Interestingly, the decrease of absorption peak of DPBF at $410 \mathrm{~nm}$ was more swiftly after the adding of $\mathrm{H}_{2} \mathrm{O}_{2}$ (Fig. 4d), proving that the ${ }^{1} \mathrm{O}_{2}$ production rate was improved. Such a distinct difference in the absorption 
peaks decreasing-rate of DPBF suggested that the LMM@BSA could trigger the decomposition of $\mathrm{H}_{2} \mathrm{O}_{2}$ to produce $\mathrm{O}_{2}$. These dissolved $\mathrm{O}_{2}$ molecules took part in the photosensitization of $\mathrm{Ce} 6$ and then enhanced the production of ROS.

\section{In vitro combined tumor therapy}

The in vitro tumor PTT efficiency was examined with HT29 cells. Upon the laser irradiation, the viability of HT29 cells decreased with the increasing of LMM@ BSA clay nanosheets concentration $(0-500 \mu \mathrm{g} /$ $\mathrm{mL}$ ) and attenuated to $14.2 \pm 1.4 \%$ when the LMM@ BSA clay nanosheets reached $500 \mu \mathrm{g} / \mathrm{mL}$ (Additional file 1: Fig. S8a). By fixing the LMM@BSA at $500 \mu \mathrm{g} /$ $\mathrm{mL}$, the HT29 cells' viability declined gradually with the enhancement of power density and a low viability of $14.6 \pm 0.1 \%$ was found at the laser power density of $1.0 \mathrm{~W} / \mathrm{cm}^{2}$ (Additional file 1: Fig. S9a). Consistent with the CCK-8 results, the calcein-AM/PI dyeing further demonstrated that the cellular apoptosis relies on nanosheets concentration and laser power density (Additional file 1: Figs. S8b-d and S9b-f), giving more evidence that the NIR laser-caused local hyperthermia could inhibit the cellular proliferation. Based on the concentration and power density-dependent tumor-killing effect, LMM@BSA clay nanosheets with a concentration of $100 \mu \mathrm{g} / \mathrm{mL}$ and $808 \mathrm{~nm}$ laser with a power density of $1.0 \mathrm{~W} / \mathrm{cm}^{2}$ were applied for the synergistic tumor therapy.

With the proved catalytic activity, LMM@BSA clay nanosheets are anticipated to enhance the tumor PDT efficiency after Ce6 loading. To prove this hypothesis, HT29 cells were used as the model to research the in vitro tumor PDT efficiency. The apoptosis extent of HT29 was correlated to the irradiation time, and the cell viability decreased to $40.3 \pm 6.0 \%$ after 5 min irradiation. The cellular viability of HT29 cells treated with LMM@BSA and LMM@BSA/Ce6 nanosheets decreased to $86.6 \pm 1.7 \%$ and $41.7 \pm 3.3 \%$ respectively after the laser irradiation (Fig. 4g-i and Additional file 1: Fig. S10). Interestingly, the cellular viability of HT29 cells attenuated to $13.8 \pm 1.3 \%$ after successively exposed to $808 \mathrm{~nm}$ and $660 \mathrm{~nm}$ laser, clearly indicating the combination of tumor PTT and PDT.

\section{In vivo compatibility}

To assess the in vivo biocompatibility, the body weight of mice (I.V. injected with LMM@BSA) was observed, which showed a normal fluctuation during 14 days feeding (Fig. 5a). The routine blood and serum biochemistry tests results displayed negligible statistical differences

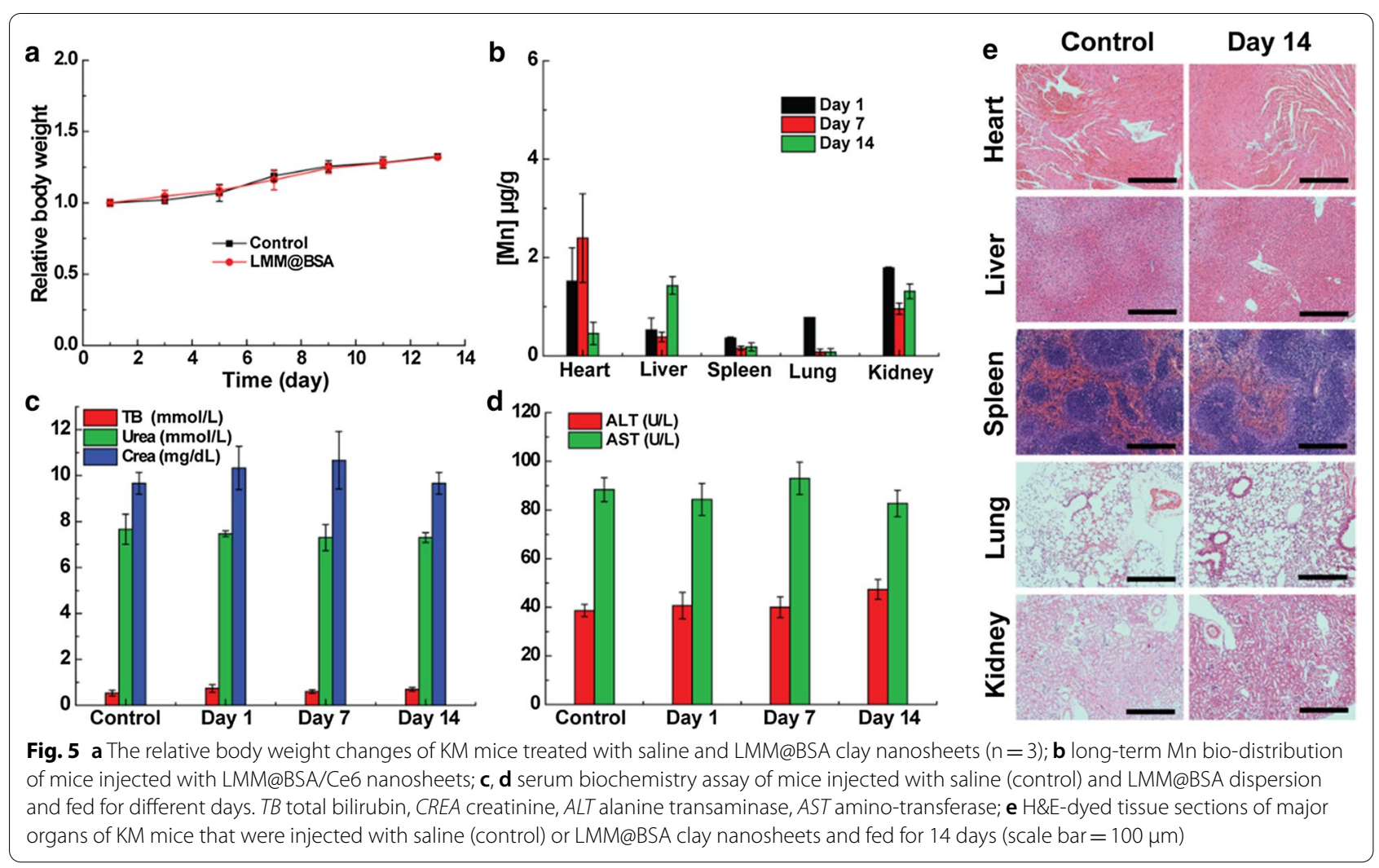


between the control and the test groups (Fig. 5c, d and Additional file 1: Fig. S11), further revealing the outstanding blood cell safety of the LMM@BSA clay nanosheets. The in vivo biocompatibility was then studied by performing the bio-distribution study of nanosheets. The results proved that the Mn levels in major organs gradually attenuated over the feeding time, indicating that LMM@BSA clay nanosheets could be excreted out of these organs (Fig. 5b). Notably, the Mn content in liver remained a relative high level after 14 days, indicating the in vivo clearance of the injected LMM@BSA was mainly happened in liver. The nanosheets' long-term biosafety and histocompatibility were finally tracked by H\&E dyeing of major organs (Fig. 5e and Additional file 1: Fig. S12). Compared with healthy mice, the LMM@BSA clay nanosheets neither brought any off-target detriment nor pathological effect to normal organs during the feeding, further supporting the excellent biosafety of nanosheets.

\section{In vitro and in vivo MR imaging}

Manganese-based nanomaterial has been frequently studied as the imaging contrast for $\mathrm{T}_{1}$-weighted $\mathrm{MR}$ imaging. Interestingly, such an imaging capacity was well-inherited by the LMM@BSA clay nanosheets. Moreover, the MR imaging is responsive in tumor microenvironment (i.e., mildly acidic and GSH). The brightness intensity of LMM@BSA clay nanosheets increased with its concentration. Surprisingly, owing to its fast break-up in acidic condition, the imaging pictures of nanosheets dispersed in acidic buffer $(\mathrm{pH}=5.0)$ were brighter than in distilled water. The brightness was detected as 4184 , 4236 and 4411 when its concentration was $0.25,0.50$, $1.0 \mathrm{mg} / \mathrm{mL}$, respectively in citric acid buffer $(\mathrm{pH}=5.0)$. In distilled water, however, it was only recorded as 2972 , 3060 and 3173. Moreover, the solution brightness in GSH increased to 3274, 3283, and 3681, which is higher than that in distilled water, probably owing to the fast-dissolving and reduction of $\mathrm{Mn}^{3+}$ to $\mathrm{Mn}^{2+}$ by GSH (Fig. 6a, b). The MR imaging capacity of LMM@BSA clay nanosheets was further evaluated in vivo on Balb/c mice that were I.V. or I.T. injected with the LMM@BSA clay nanosheets. A remarkable increase of brightness intensity could be observed within the tumor site after the I.V. (RBI: 1.6, Fig. $6 \mathrm{c}-\mathrm{e}$ ) or I.T. (RBI: 2.7, Fig. 6c, d, f) injection, which provides the powerful proof for the promising in vivo MR imaging and diagnosing of tumor.

\section{In vivo combined tumor therapy}

The tumor treatment effectiveness of LMM@BSA/Ce6 nanosheets was finally verified on tumor-bearing mice (HT29 colorectal carcinoma, Fig. 7). Due to the photothermal efficiency, the tumor surface temperature of the mice with I.V. or I.T. LMM@BSA injection raised by $\sim 16{ }^{\circ} \mathrm{C}$ or $\sim 33{ }^{\circ} \mathrm{C}$ upon the $5 \mathrm{~min} 808 \mathrm{~nm}$ laser irradiation. However, no noticeable temperature changes were found in the control group (Fig. 7a). In vivo imaging of mice further proved the photo-thermal effect of LMM@BSA and the neglectable thermal effect of saline (Fig. 7c). Subsequently, the therapy efficiency was monitored by measuring the tumor volume and recording digital photographs (Fig. 7b, d). The tumor volume of the control group was about $5.7 \pm 1.2$ times larger than the original after 28 days feeding. After single laser irradiation, the tumor expanded $3.0 \pm 0.2(660 \mathrm{~nm})$ and $1.9 \pm 0.1$ times $(808 \mathrm{~nm})$ of its volume after 28 days feeding, manifesting that the individual PTT or PDT therapy could inhibit the tumor growth to some extent. Notably, the tumor volume shrank to approximate $40 \%$ of the original (I.V. injection) and were eradicated (I.T. injection) after the combined PDT and PTT, visually illustrating that the combination of hyperthermia and ROS produced the excellent tumor restraining-effect.

\section{Drug loading and releasing behavior}

In addition to Ce6, the LMM@BSA clay nanosheets could also work as a carrier to physically load antitumor drugs (e.g., DOX) and control its release. The optimized DOX loading efficiency was calculated as $66.9 \%$. The drug release pattern was plotted by changing external conditions. The releasing rate was lower than $10 \%(6.2 \%)$ in neutral condition $\left(50{ }^{\circ} \mathrm{C}\right)$. However, it was significantly improved in the acidic condition $(\mathrm{pH}=6.0)$, which reached $54.9 \%$ and $52.3 \%$ under $37^{\circ} \mathrm{C}$ and $54{ }^{\circ} \mathrm{C}$, respectively (Fig. 4e). The DOX was also released more swiftly in higher temperature, meaning that the NIR would promote the drug-releasing. This DOX releasing kinetics with $\mathrm{pH}$ and temperature (NIR laser)-dependent properties could equip the LMM@BSA clay nanosheets with competitiveness for tumor chemotherapy, which would be discussed in the future study.

\section{Conclusion}

In summary, a novel kind of biocompatible $\mathrm{Mg}-\mathrm{Mn}-\mathrm{Al}$ LDH-based nano-platform, namely LMM@BSA which could integrate the photo-thermal effect of $\mathrm{MoS}_{2}$ was synthesized using a hydrothermal approach. The surface of LMM was coated with BSA to render it with excellent colloidal stability under physiological conditions. Owing to the fast break-up in acidic conditions and the reduction of $\mathrm{Mn}^{3+}$ to $\mathrm{Mn}^{2+}$ by GSH in tumor micro-environment, the $\mathrm{MR}$ imaging of $\mathrm{Mg}-\mathrm{Mn}-\mathrm{Al}$ LDH was strengthened. Notably, the interlayer space and the surface of LMM@BSA clay nanosheets could be 


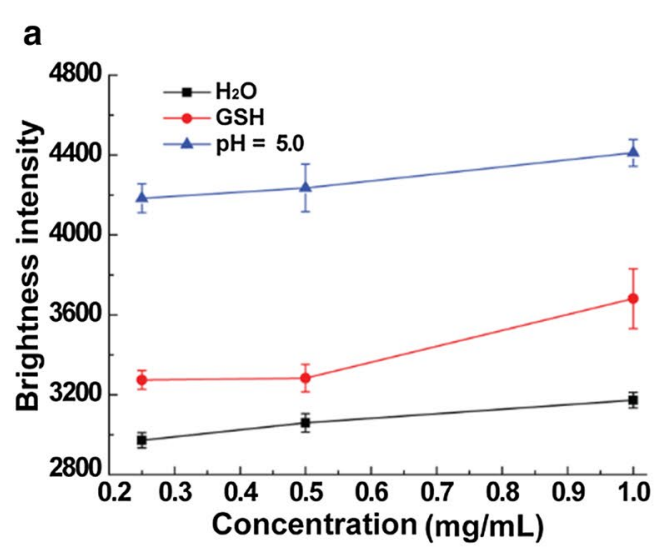

b

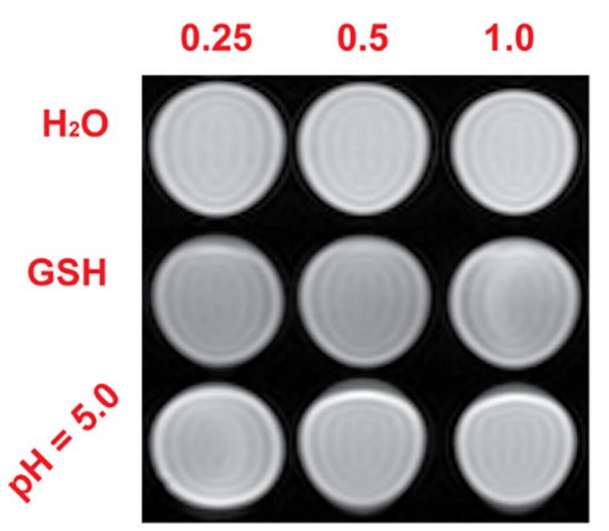

C

d
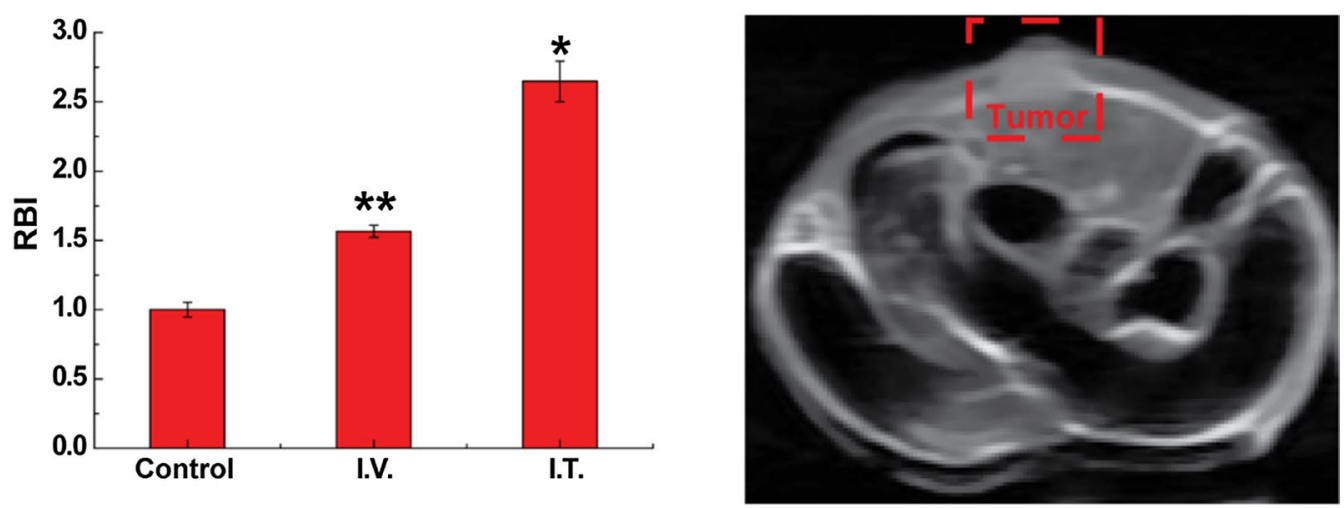

e

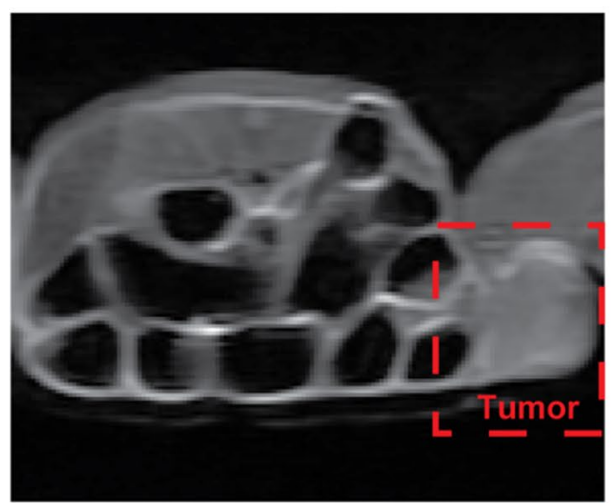

f

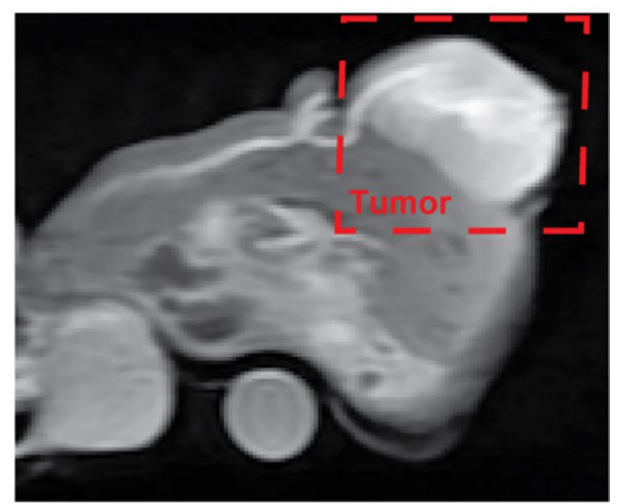

Fig. 6 a In vitro brightness intensity of LMM@BSA in a mildly acidic environment $(\mathrm{pH}=5.0)$, distilled water or GSH aqueous solutions after soaking at $37^{\circ} \mathrm{C}$ for $2 \mathrm{~h} ; \mathbf{b} \mathrm{T}_{1}$-weighted MR imaging of solution corresponding to $\mathbf{a}$, unit: $\mathrm{mg} / \mathrm{mL} ; \mathbf{c}$ in vivo relative brightness intensity of mice tumor after I.T. or I.V. injected with saline and LMM@BSA; $\mathbf{d}$-f in vivo T,-weighted MR imaging corresponded to $\mathbf{c}$, (d control, e I.V., and f I.T.)

used to efficiently load Ce6. The ROS production of Ce6 under the light irradiation was distinctively enhanced since the LMM@BSA could catalyze the decomposing of $\mathrm{H}_{2} \mathrm{O}_{2}$ in the tumor to produce oxygen. In addition, the high photo-thermal conversion efficiency of the
$\mathrm{MoS}_{2}$ component could elevate the local temperature of tumor, which successfully achieved a remarkable PTT and PDT combined anticancer outcome. Compared with other kinds of nanocarriers, the LMM holds a more promising future to carry guest molecules since 

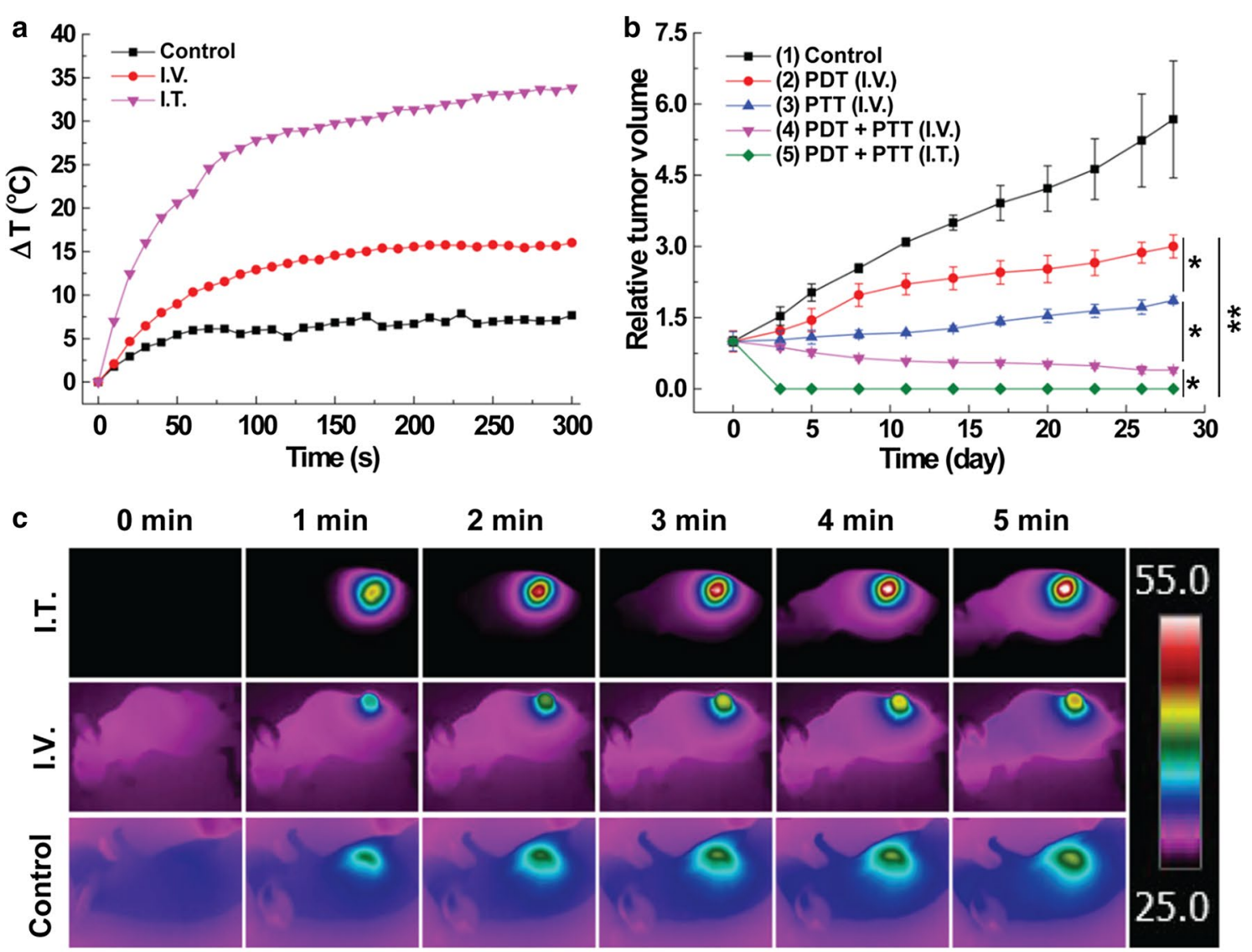

$5 \mathrm{~min}$

d

(1)

(2)

(3)

(4)
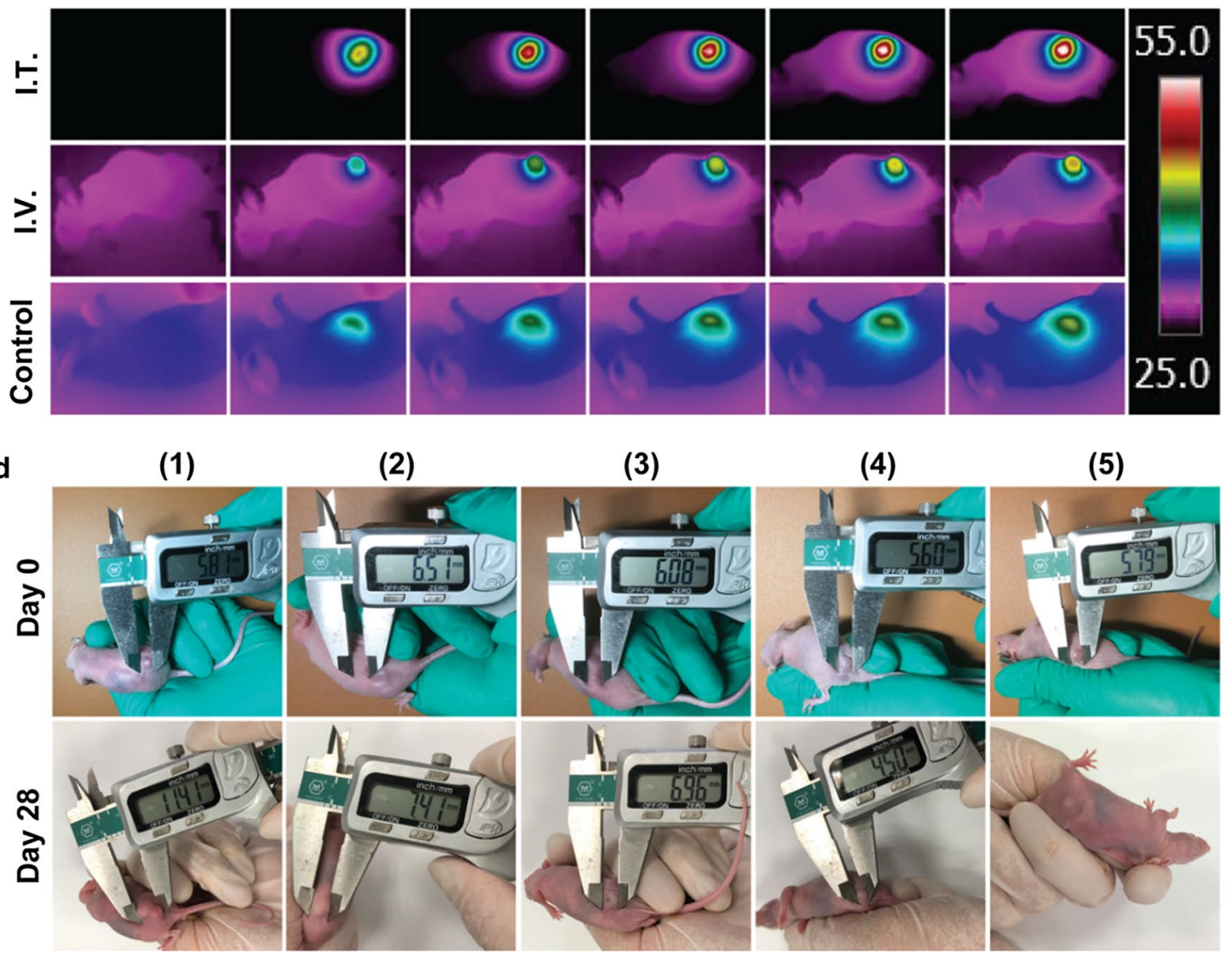

(5)
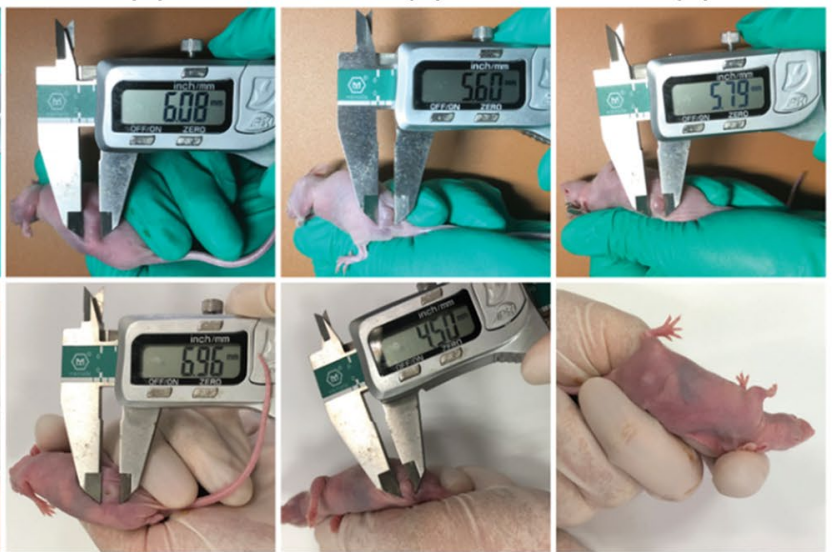

Fig. 7 a The tumor heating curves of mice under NIR laser irradiation; $\mathbf{b}$ tumor growth profile of mice after various treatments as noted; $\mathbf{c}$ in vivo thermal imaging of mice after laser irradiation for different time points corresponding to $\mathbf{a}$; $\mathbf{d}$ pictures of HT29 tumor-bearing mice at day 0 and day 28 corresponding to $\mathbf{b}$. The unit of the bar in $\mathbf{c} ~^{\circ} \mathrm{C}$

it has not only the interlayer space, but also the unique 2D morphology. Although this synthetic LMM@BSA is not degradable, this work presents an advances in the rational design of LDH-based cancer-therapeutic modalities with simultaneous low side effects and high therapeutic results. 


\section{Supplementary Information}

The online version contains supplementary material available at https://doi. org/10.1186/s12951-020-00763-7.

Additional file 1: Figure S1. (a) AFM image of $L M M @ B S A$, (b) the height of LMM@BSA. Figure S2. XPS spectra of LMM: (a) Mo 3d, (b) Al 2p, (c) $\mathrm{Mg} 1 \mathrm{~s}$ and (d) S 2p. Figure S3. Dynamic light scattering of LMM@BSA nanosheets dispersed in DMEM. Figure S4. (a) Cell viability profiles; (b-f) appearance of calcein-AM/PI dyed L929 cells treated with different concentration of LMM@BSA clay nanosheets (incubation time: $24 \mathrm{~h}$ ): (b) control; (c) $50 \mu \mathrm{g} / \mathrm{mL}$; (d) $100 \mu \mathrm{g} / \mathrm{mL}$; (e) $250 \mu \mathrm{g} / \mathrm{mL}$; (f) $500 \mu \mathrm{g} / \mathrm{mL}$. Figure S5. (a, b) The morphology of cell treated with (a) saline and (b) LMM@BSA clay nanosheets $(500 \mu \mathrm{g} / \mathrm{mL})$. Figure $\mathbf{S 6}$. Hemolysis percentage of mRBCs co-incubated with LMM@BSA clay nanosheets (concentration: 0-500 $\mathrm{\mu g} /$ $\mathrm{mL}$ ) for 2 h. Figure S7. UV-vis-NIR spectra of prepared nanosheets.

Figure S8. (a) Cell viability profiles; (b-d) appearance of calcein-AM/PI dyed cells after PTT treatments $\left(1 \mathrm{~W} / \mathrm{cm}^{2}\right)$ with different concentration

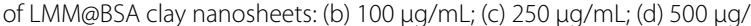
$\mathrm{mL}$. Figure S9. (a) Cell viability profiles after different treatments; $(b-g)$ appearance of calcein-AM/PI stained cells treated with (b) DMEM + saline without laser; (c) DMEM + LMM@BSA without laser; (d-g) DMEM + LMM@ BSA with laser of (d) $0.2 \mathrm{~W} / \mathrm{cm}^{2}$; (e) $0.5 \mathrm{~W} / \mathrm{cm}^{2}$; (f) $0.8 \mathrm{~W} / \mathrm{cm}^{2}$; (g) $1.0 \mathrm{~W} /$ $\mathrm{cm}^{2}$. Control: $02 \mathrm{~W} / \mathrm{cm}^{2}$. Figure S10. (a) Cell viability profiles treated with LMM@BSA/Ce6 annd $660 \mathrm{~nm}$ laser $\left(0.1 \mathrm{~W} / \mathrm{cm}^{2}\right)$ irradiation for different time points; $(b-f)$ appearance of calcein-AM/PI stained cells after PDT treatments with varied irradiated duration: (b) $0 \mathrm{~min}$; (c) $1 \mathrm{~min}$; (d) 2 min; (e) $3 \mathrm{~min}$; (f) $5 \mathrm{~min}$. Figure S11. The routine blood test of mice (a) white blood cell (WBC); (b) red blood cells (RBC); (c) hemoglobin (HGB); (d) hematocrit (HCT); (e) mean corpuscular volume (MCV); (f) mean corpuscular hemoglobin (MCH); (g) mean corpuscular hemoglobin concentration (MCHC); (h) platelet (PLT); and (i) red cell distribution width (RDW) with feeding for varied days. Figure S12. H\&E-stained tissue sections of major organs of KM mice that injected with saline or LMM@BSA/Ce6 nanosheets and fed for 1 and 7 days.

\section{Acknowledgements}

J. Z. and H. W. contributed equally to this work. This work was financially supported by Medicine \& Engineering Cross Research Foundation between Changhai Hosipital and University of Shanghai for Science and Technology. Authors also thanks the financial support of Shanghai Rising-Star Program (20QA1407200).

\section{Authors' contribution}

$J Z$ is responsible for the data curation, investigation, writing and original draft. HW did the data curation, and wrote the original draft. JZ did the software analysis. YY worte and reviewed the manuscript. ZZ is responsible for writing review and editing. SW did the validation. $\mathrm{KL}$ is responsible for the conceptualization, methodology, funding acquisition, supervision. All authors read and approved the final manuscript.

\section{Competing interests}

The authors declare that they have no competing interests.

\section{Author details}

${ }^{1}$ Department of Gastroenterology, Changhai Hospital, Second Military Medical University, No. 168 Changhai Road, Shanghai 200433, People's Republic of China. ${ }^{2}$ College of Science, University of Shanghai for Science and Technology, No. 334 Jungong Road, Shanghai 200093, People's Republic of China. ${ }^{3}$ Department of General Surgery, Xinhua Hospital, Shanghai Jiaotong University School of Medicine, No. 1665 Kongjiang Road, Shanghai 200433, People's Republic of China.

Received: 20 November 2020 Accepted: 26 December 2020 Published online: 03 February 2021

\section{References}

1. Miller KD, Nogueira L, Mariotto AB, Rowland JH, Yabroff KR, Alfano CM, Jemal A, Kramer JL, Siegel RL. Cancer treatment and survivorship statistics, 2019. CA Cancer J Clin. 2019;10(5):685-9.

2. Siegel RL, Miller KD, Fedewa SA, Ahnen DJ, Meester RGS, Barzi A, Jemal A. Colorectal cancer statistics, 2017. CA Cancer J Clin. 2017;67(3):177-93.

3. Zhou L, Zhao J, Chen Y, Zheng Y, Li J, Zhao J, Zhang J, Liu Y, Liu X, Wang S. $\mathrm{MoS}_{2}$-ALG-Fe/GOx hydrogel with Fenton catalytic activity for combined cancer photothermal, starvation, and chemodynamic therapy. Colloid Surf B. 2020;195:111243.

4. Jemal A, Bray F, Center MM, Ferlay J, Ward E, Forman D. Global cancer statistics. CA Cancer J Clin. 2011;61(2):134

5. Xiao Q, Zheng X, Bu W, Ge W, Zhang S, Chen F, Xing H, Ren Q, Fan W, Zhao K, Hua Y, Shi J. A core/satellite multifunctional nanotheranostic for in vivo imaging and tumor eradication by radiation/photothermal synergistic therapy. J Am Chem Soc. 2013;135(35):13041-8.

6. Liu T, Wang C, Cui W, Gong H, Liang C, Shi X, Li Z, Sun B, Liu Z. Combined photothermal and photodynamic therapy delivered by PEGylated $\mathrm{MoS}_{2}$ nanosheets. Nanoscale. 2015;6:11219-25.

7. Nakae T, Uto Y, Tanaka M, Shibata H, Nakata E, Tominaga M, Maezawa $\mathrm{H}$, Hashimoto T, Kirk KL, Nagasawa H, Hori H. Design, synthesis, and radiosensitizing activities of sugar-hybrid hypoxic cell radiosensitizers. Bioorgan Med Chem. 2008;16(2):675-82.

8. Hainfeld JF, Dilmanian FA, Slatkin DN, Smilowitz HM. Radiotherapy enhancement with gold nanoparticles. J Pharm Pharmacol. 2008;60(8):977-85.

9. Zheng Y, Wang W, Zhao J, Wu C, Ye C, Huang M, Wang S. Preparation of injectable temperature-sensitive chitosan-based hydrogel for combined hyperthermia and chemotherapy of colon cancer. Carbohydr Polym. 2019;222:115039

10. Xu Y, Zhao J, Zhang Z, Zhang J, Huang M, Wang S, Xie P. Preparation of electrospray ALG/PDA-PVP nanocomposites and their application in cancer therapy. Soft Matter. 2019;16(16):132-41.

11. Li W, Wang X, Wang J, Guo Y, Lu S-Y, Li CM, Kang Y, Wang Z-G, Ran H-T, Cao $Y$, Liu H. Enhanced photoacoustic and photothermal effect of functionalized polypyrrole nanoparticles for near-infrared theranostic treatment of tumor. Biomacromolecules. 2019;20(1):401-11.

12. Lin L, Cong Z, Cao J, Ke K, Peng Q, Gao J, Yang H, Liu G, Chen X. Multifunctional $\mathrm{Fe}_{3} \mathrm{O}_{4} @$ polydopamine core-shell nanocomposites for intracellular mRNA detection and imaging-guided photothermal therapy. ACS Nano. 2014;8(4):3876-83.

13. Yang B, Chen $Y$, Shi J. Material chemistry of two-dimensional inorganic nanosheets in cancer theranostics. Chem. 2018;4(6):1284-313.

14. Macharia DK, Tian Q, Chen L, Sun Y, Yu N, He C, Wang H, Chen Z. PEGylated $\left(\mathrm{NH}_{4}\right) \times \mathrm{WO}_{3}$ nanorods as efficient and stable multifunctional nanoagents for simultaneous CT imaging and photothermal therapy of tumor. J Photochem Photobiol B. 2017:174:10-7.

15. Liu B, Li C, Chen G, Liu B, Deng X, Wei Y, Xia J, Xing B, Ma PA, Lin J. Synthesis and optimization of $\mathrm{MoS}_{2} @ \mathrm{Fe}_{3} \mathrm{O}_{4}-\mathrm{ICG} / \mathrm{Pt}(\mathrm{IV})$ nanoflowers for MR/IR/PA boimaging and combined PTT/PDT/chemotherapy triggered by $808 \mathrm{~nm}$ laser. Adv Sci. 2017;4(8):1600540.

16. Gao S, Zhou HL, Cui SM, Shen H. Bottom-up synthesis of MoS 2 nanospheres for photothermal treatment of tumors. Photochem Photobiol Sci. 2018;17(10):1337-45.

17. Wei J, Li J, Sun D, Li Q, Ma J, Chen X, Zhu X, Zheng N. A novel theranostic nanoplatform based on Pd@Pt-PEG-Ce6 for enhanced photodynamic therapy by modulating tumor hypoxia microenvironment. Adv Funct Mater. 2018;28(17):1-12.

18. Kuo W-S, Chang C-N, Chang Y-T, Yang M-H, Chien Y-H, Chen S-J, Yeh C-S. Gold nanorods in photodynamic therapy, as hyperthermia agents, and in near-infrared optical imaging. Angew Chem Int Ed. 2010;49(15):2711-5.

19. Wang J, Zhu G, You M, Song E, Shukoor MI, Zhang K, Altman MB, Chen Y, Zhu Z, Huang CZ, Tan W. Assembly of aptamer switch probes and photosensitizer on gold nanorods for targeted photothermal and photodynamic cancer therapy. ACS Nano. 2012;6(6):5070-7.

20. Gao L, Fei J, Zhao J, Li H, Cui Y, Li J. Hypocrellin-loaded gold nanocages with high two-photon efficiency for photothermal/hotodynamic cancer therapy in vitro. ACS Nano. 2012;6(9):8030-40. 
21. Jang B, Park J-Y, Tung C-H, Kim I-H, Choi Y. Gold nanorod-photosensitizer complex for near-infrared fluorescence imaging and photodynamic/photothermal therapy in vivo. ACS Nano. 2011;5(2):1086-94.

22. Tian B, Wang C, Zhang S, Feng L, Liu Z. Photothermally enhanced photodynamic therapy delivered by nano-graphene oxide. ACS Nano. 2011;5(9):7000-9.

23. Chen Z, Li Z, Wang J, Ju E, Zhou L, Ren J, Qu X. A multi-synergistic platform for sequential irradiation-activated high-performance apoptotic cancer therapy. Adv Funct Mater. 2014;24(4):522-9.

24. Li F, Park S-J, Ling D, Park W, Han JY, Na K, Char K. Hyaluronic acid-conjugated graphene oxide/photosensitizer nanohybrids for cancer targeted photodynamic therapy. J Mater Chem B. 2013;1(12):1678-86.

25. Gong H, Cheng L, Xiang J, Xu H, Feng L, Shi X, Liu Z. Near-infrared absorbing polymeric nanoparticles as a versatile drug carrier for cancer combination therapy. Adv Funct Mater. 2013;23(48):6059-67.

26. Sherlock SP, Tabakman SM, Xie L, Dai H. Photothermally enhanced drug delivery by ultrasmall multifunctional FeCo/graphitic shell nanocrystals. ACS Nano. 2011;5(2):1505-12.

27. Dong K, Liu Z, Li Z, Ren J, Qu X. Hydrophobic anticancer drug delivery by a $980 \mathrm{~nm}$ laser-driven photothermal vehicle for efficient synergistic therapy of cancer cells in vivo. Adv Mater. 2013;25(32):4452-8.

28. Mi P, Kokuryo D, Cabral H, Wu HL, Terada Y, Saga T, Aoki I, Nishiyama N, Kataoka K. A pH-activatable nanoparticle with signal-amplification capabilities for non-invasive imaging of tumour malignancy. Nat Nanotechnol. 2016;11(8):724

29. Guo B, Zhao J, Zhang Z, An X, Huang M, Wang S. Intelligent nanoenzymebased theranostic agent for $T_{1}$-weighted MR imaging and combined tumor photo-therapy. Chem Eng J. 2020;382:123609.

30. Wang J, Wang X, Lu S-Y, Hu J, Zhang W, Xu L, Gu D, Yang W, Tang W, Liu F, Cao Y, Liu H. Integration of cascade delivery and tumor hypoxia modulating capacities in core-releasable satellite nanovehicles to enhance tumor chemotherapy. Biomaterials. 2019;223:119465.

31. Khatoon N, Chu MQ, Zhou CH. Nanoclay-based drug delivery systems and their therapeutic potentials. J Mater Chem B. 2020;8(33):7335-51.

32. Wang S, Zhou L, Zheng Y, Li L, Wu C, Yang H, Huang M, An X. Synthesis and biocompatibility of two-dimensional biomaterials. Colloid Surf A. 2019;583:124004.

33. Wang Q, O'Hare D. Recent advances in the synthesis and application of layered double hydroxide (LDH) nanosheets. Chem Rev. 2012;112(7):4124-55.

34. Zhao M-Q, Zhang Q, Huang J-Q, Wei F. Hierarchical nanocomposites derived from nanocarbons and layered double hydroxides-properties, synthesis, and applications. Adv Funct Mater. 2012;22(4):675-94.
35. Ma J, Duan P, Ren D, Zhou W. Effects of layered double hydroxides incorporation on carbonation resistance of cementitious materials. J Mater Res Technol. 2019;8(1):292-8.

36. Evans DG, Duan X. Preparation of layered double hydroxides and their applications as additives in polymers, as precursors to magnetic materials and in biology and medicine. Chem Commun. 2006;5:485-96.

37. Williams GR, O'Hare D. Towards understanding, control and application of layered double hydroxide chemistry. J Mater Chem B. 2006;16(30):3065-74

38. Khan Al, O'Hare D. Intercalation chemistry of layered double hydroxides: recent developments and applications. J Mater Chem B. 2002;12(11):3191-8.

39. Barnabas MJ, Parambadath S, Nagappan S, Ha CS. Sulfamerazine schiffbase complex intercalated layered double hydroxide: synthesis, characterization, and antimicrobial activity. Heliyon. 2019;5(4):e01521.

40. Yang W, Guo W, Chang J, Zhang B. Protein/peptide-templated biomimetic synthesis of inorganic nanoparticles for biomedical applications. J Mater Chem B. 2017;5(3):401-17.

41. Feng W, Han X, Wang R, Gao X, Hu P, Yue W, Chen Y, Shi J. Nanocatalystsaugmented and photothermal-enhanced tumor-specific sequential nanocatalytic therapy in both NIR-I and NIR-II biowindows. Adv Mater. 2019;31(5):1805919.

42. Tian Q, Hu J, Zhu Y, Zou R, Chen Z, Yang S, Li R, Su Q, Han Y, Liu X. Sub-10 $\mathrm{nm} \mathrm{Fe}_{3} \mathrm{O}_{4} @ \mathrm{Cu}_{2-x} \mathrm{~S}$ core-shell nanoparticles for dual-modal imaging and photothermal therapy. J Am Chem Soc. 2013;135(23):8571-7.

43. Zhao Y, Li F, Zhang R, Evans DG, Duan X. Preparation of layered doublehydroxide nanomaterials with a uniform crystallite size using a new method involving separate nucleation and aging steps. Chem Mater. 2002;14(10):4286-91.

44. Li S, Guo Y, Xiao M, Zhang T, Yao S, Zang S, Fan H, Shen Y, Zhang Z, Li W. Enhanced arsenate removal from aqueous solution by $\mathrm{Mn}$-doped MgAllayered double hydroxides. Environ Sci Pollut Res. 2019;26(12):12014-24.

45. Liu T, Wang C, Gu X, Gong H, Cheng L, Shi X, Feng L, Sun B, Liu Z. Drug delivery with PEGylated $\mathrm{MoS}_{2}$ nano-sheets for combined photothermal and chemotherapy of cancer. Adv Mater. 2014;26(21):3433-40.

46. Yin W, Yan L, Yu J, Tian G, Zhou L, Zheng X, Zhang X, Yong Y, Li J, Gu Z, Zhao $Y$. High-throughput synthesis of single-layer $M_{0} S_{2}$ nanosheets as a near-infrared photothermal-triggered drug delivery for effective cancer therapy. ACS Nano. 2014;8(7):6922-33.

\section{Publisher's Note}

Springer Nature remains neutral with regard to jurisdictional claims in published maps and institutional affiliations.
Ready to submit your research? Choose BMC and benefit from:

- fast, convenient online submission

- thorough peer review by experienced researchers in your field

- rapid publication on acceptance

- support for research data, including large and complex data types

- gold Open Access which fosters wider collaboration and increased citations

- maximum visibility for your research: over $100 \mathrm{M}$ website views per year

At BMC, research is always in progress.

Learn more biomedcentral.com/submissions 